\title{
Synthesis of Graphene Oxide-Polystyrene Graft Polymer Based on Reversible Addition Fragmentation Chain Transfer and Its Effect on Properties, Crystallization, and Rheological Behavior of Poly (Lactic Acid)
}

\author{
Li Yang and Weijun Zhen \\ Key Laboratory of Oil and Gas Fine Chemicals, Ministry of Education and Xinjiang Uygur Autonomous Region, Xinjiang University, \\ Urumqi 830046, China \\ Correspondence should be addressed to Weijun Zhen; zhenweijun6900@163.com
}

Received 6 May 2020; Revised 6 July 2020; Accepted 7 July 2020; Published 29 July 2020

Academic Editor: Iza Radecka

Copyright (C) 2020 Li Yang and Weijun Zhen. This is an open access article distributed under the Creative Commons Attribution License, which permits unrestricted use, distribution, and reproduction in any medium, provided the original work is properly cited.

\begin{abstract}
Graphene oxide-polystyrene graft polymer (SGO-PS) was prepared by reversible addition-fragmentation chain transfer radical polymerization method. Orthogonal experiments indicated that the optimum synthesis reaction conditions for SGO-PS were as follows: the millimole ratio of chain transfer agent to initiator was $0.15: 0.3$, and the amount of styrene was $8 \mathrm{~mL}$ at $80^{\circ} \mathrm{C}$ for 12 hours. The products were characterized by Fourier transform infrared spectroscopy and thermal weightlessness analysis, and the highest grafting rate of SGO-PS was $62.46 \%$. Then, PLA/SGO-PS nanocomposites were prepared using SGO-PS as fillers by melt intercalation method, and its crystallinity, mechanical properties, and thermal stability were significantly improved. Compared with pure PLA, the crystallinity of PLA/SGO-PS (0.3 wt\%) nanocomposites was increased by 5 times. Multiple melting behavior tests showed that the introduction of SGO-PS caused the PLA molecular chain to be discharged into the unit cell in time, and the melting temperature shifted to a higher temperature, which ultimately made the grain structure of PLA composites more complete and stable than pure PLA. The rheological performance test showed that the uniform dispersion of SGO-PS in the PLA matrix inhibited the free movement of the PLA molecular chain and caused higher flow resistance, resulting in an increase in the complex viscosity, storage modulus, and loss modulus of PLA/SGO-PS.
\end{abstract}

\section{Introduction}

Plastic materials have been widely used in all aspects of life and industry. However, most conventional plastics are nonbiodegradable, and their accumulation in the environment has threatened the ecological balance of the earth [1]. Concerns about environmental protection and the shortage of petroleum resources have promoted the production of biodegradable materials [2,3]. Poly (lactic acid) (PLA) is one kind of biodegradable [4] and biocompatible thermoplastic that is fermented from renewable resources. PLA can be completely decomposed into environmentalfriendly $\mathrm{CO}_{2}$ and $\mathrm{H}_{2} \mathrm{O}$ under the condition of composting, so its characteristics have attracted much attention in the research of polymer materials [5-9]. Since the lactic acid molecule has an asymmetric carbon atom, it has optical rotation. However, due to the poor chemical regularity of PLA [10], its relatively low thermal stability, inherent brittleness, low toughness, and low crystallinity [11] limit its further application and development [12-14]. Therefore, it is necessary to modify PLA to expand its practical application in various fields.

Therefore, in order to improve the above defects of PLA and broaden its application range, it is necessary to study the modification of PLA. At present, the modification of PLA mainly includes chemical modification and physical modification [15]. Chemical modification of PLA refers to a monomer or a reactive group in the form of a covalent bond 
with poly (lactic acid) chemical combination, mainly includes the copolymerization modification [16], chain extension modification [17], graft modification [18], and crosslinking modification [19]. The physical modification of PLA mainly includes the blending of PLA with other high-performance polymer materials, and filling with inorganic compounds, organic compounds, and macromolecules by various methods [20]. Physical modification can not only reduce the cost of PLA to a certain extent but also improve the defects of PLA on the basis of maintaining its original excellent performance, so as to expand the practical use range of PLA.

Graphene oxide (GO) is a monoatomic layer made of graphite powder through chemical oxidation and stripping. Its lateral size can be extended from nanometers to micrometers. Due to its special mechanical properties, thermal properties, high specific surface area, and unique twodimensional structure compared with clay, carbon nanotubes, graphite, and other composite materials, it is very suitable for the construction of high-performance polymer-based nanocomposites [21]. The surface of GO has a large number of oxygen-containing functional groups, such as carboxyl (-COOH), hydroxyl $(-\mathrm{OH})$, and epoxy functional groups (C-O-C) [22]. These polar groups can make the polymer easily embedded in the graphene oxide layer to form a poly (lactic acid) nanocomposite, thereby effectively improving the mechanical properties of the polymer composite, the thermal properties, and the crystalline properties. However, in polymer/GO composites, incompatibilities between the filler and the polymer matrix can reduce the performance of the polymer material. In order to improve the dispersion and compatibility of graphene oxide in the poly (lactic acid) matrix, the surface of graphene oxide can be modified by polymers. Wang et al. [23] introduced chain extender (CE) and hydroxylfunctionalized graphene (HG) into PLA by melt blending to improve crystallization behaviors, rheological properties, and foaming behaviors of PLA. The results showed that the cold crystallization temperature of the chain extended PLA (CPLA)/HG was higher $8.2^{\circ} \mathrm{C}$ than that of PLA and the viscoelasticity of PLA was improved, which due to the formation of branching structure and the interaction between CPLA and HG. Wang et al. [10] used poly (ethylene octene) grafted with glycidyl methacrylate (POE-gGMA) to improve rheological, thermal properties, toughness, and foaming properties of PLA through chain extension. The results showed that the dynamic rheology of PLA was significantly improved, the cold crystallization temperature of PLA decreased by more than $10^{\circ} \mathrm{C}$, and the impact strength increased by more than 4 times, which was caused by the chain extension reaction between PLA and POE-g-GMA.

Atom transfer radical polymerization (ATRP) can effectively realize living polymerization and has the characteristics of controllable molecular weight and narrow molecular weight distribution. Some researchers, such as RoghaniMamaqani and Haddadi-Asl [24], carried out such ATRP reactions on the hydroxyl groups on GO to functionalize GO with (3-aminopropyl) triethoxysilane coupling agent. Subsequently, the functionalized GO was reacted with $\alpha$-bro- moisobutyl to form an initiator macromolecule, and a graft of GO-polystyrene was formed through the ATRP reaction. The electron activated regeneration atom transfer radical polymerization method (AGET-ATRP) is developed based on the ATRP principle. The biggest difference is that AGETATRP does not need to add a low-price catalyst, but introduces reducing agent (ascorbic acid) to react with oxidation state transition metal to produce the catalyst for ATRP. Zheng and Zhen [25] used AGET-ATRP polymerization to graft polymethyl methacrylate on GO and added it to PLA as a nucleating agent by melt blending to modify the PLA. The results show that the fracture elongation and impact strength of the composite have improved by $40.66 \%$ and $50.62 \%$, respectively, due to the improved crystalline properties, and the composite has strong shielding performance against ultraviolet light. However, the double bond of the monomer used for AGET-ATRP polymerization generally requires electron-absorbing groups, while the double bond of the monomer used for active cationic polymerization requires electron-pushing groups, therefore, a variety of polymerization methods should be combined to obtain the target polymer [26].

As one of the active free radical polymerization, reversible addition-fragmentation chain transfer (RAFT) has a full range of applicable monomer, a relatively mild reaction temperature, and can be achieved by a variety of polymerization methods such as bulk, solution, emulsion, and suspension polymerization [27] In general, it is necessary to introduce trace chain transfer agents (such as trithioesters) into the free radical polymerization system (monomer + initiator) to initiate polymerization [28]. Because the thiocarbonyl group in the trithiocarbonate can ensure the rapid chain transfer reaction, thereby reducing the blocking phenomenon and preparing different functional polymers. Yang et al. [29] grafted RAFT chain transfer agent (CTA) onto the surface of reduced graphene oxide (RGO) nanosheets by a click reaction, and then grafted poly ( $\mathrm{N}$-isopropylamide) onto the surface of RGO by RAFT polymerization. After a three-step modification process, Nikdel et al. [30] coupled the dithiobenzoyl disulphide (RAFT agent) to the GO surface, obtained the GO-RAFT nanosheet, and synthesized the RAFT polymerization product of 2-ethyl methacrylate and acrylic acid using azodiisobutyronitrile as the initiator. A wide range of chain transfer agents for RAFT polymerization of alternative trithioesters can be used to prepare a series of homopolymers with different and narrow molecular mass distribution, which can be applied to the modification properties of $\mathrm{GO}$ to greatly expand the application of $\mathrm{GO}$ in the field of polymer composites.

In this work, a modified GO (SGO) capable of initiating RAFT polymerization is firstly prepared through the esterification of hydroxyl groups on the surface of GO with trithiocarbonate, SGO was used as a macromolecular chain transfer agent, and azobisisobutyronitrile was used as an initiator to initiate RAFT polymerization of styrene monomer to obtain graphene oxide-grafted polystyrene (SGO-PS). Then, SGO-PS was used in the fillers in PLA, and PLA/SGO-PS nanocomposites were prepared by melt 


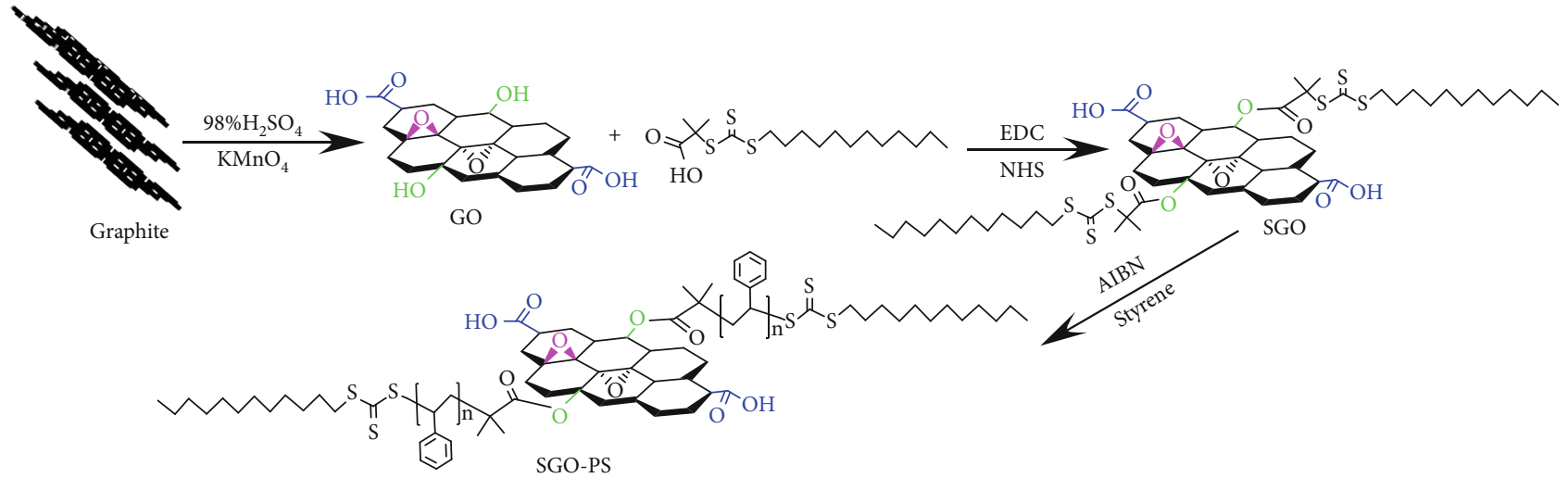

FIGURE 1: The synthesis route of SGO-PS.

intercalation. Furthermore, the effect of SGO-PS on properties, crystallization, and rheological behavior of poly (lactic acid) was investigated, respectively.

\section{Experimental}

2.1. Materials. The flake graphite had an average particle size of $75 \mu \mathrm{m}$ and was purchased from Qingdao Dahe Graphite Co. Ltd. Sulfuric acid, potassium permanganate, and hydrogen peroxide were purchased from Chengdu Kelong Chemical Reagent Factory. Hydrochloric acid was purchased from Tianjin Zhiyuan Chemical Reagent Co. Ltd. Trithiocarbonate, styrene, and azobisisobutyronitrile (AIBN) were purchased from Beijing J\&K Chemicals Co. Ltd. PLA (injection grade, $M_{w}=100000 \mathrm{~g} \cdot \mathrm{mol}^{-1}$ ) was purchased from Shenzhen Guanghua Weiye Co. Ltd. 1-(3-Dimethylaminopropyl)-3-ethyldiimine hydrochloride (EDC) was purchased from Shanghai Macklin Biochemical Technology Co. Ltd. $\mathrm{N}$-Hydroxysuccinimide (NHS) was purchased from Beijing J\& K Chemicals Co. Ltd.

2.2. Preparation of GO. GO was prepared by modified Hummers and Offeman [31]. Firstly, $150 \mathrm{~mL}$ sulfuric acid (98 wt\%) was precooled in an ice bath for 15 minutes. Then, $6 \mathrm{~g}$ graphite and $3 \mathrm{~g} \mathrm{NaNO}_{3}$ were added and stirred well at $5^{\circ} \mathrm{C}$. After adding $21 \mathrm{~g} \mathrm{KMnO}_{4}$ in batches within 1 hour, the reaction was continued for 1 hour. Furthermore, the reaction was carried on for 2 hours at $35^{\circ} \mathrm{C}$ until the solution was changed from purple to green. Subsequently, $225 \mathrm{~mL}$ of deionized water was added slowly in batches and heated to $95^{\circ} \mathrm{C}$ for 30 minutes. Then, $\mathrm{H}_{2} \mathrm{O}_{2}$ (30\%) was slowly added in batches to turn the solution into golden at $60^{\circ} \mathrm{C}$. After that, the product was filtered while hot and washed with 5\% hydrochloric acid and pure water. The product was dialyzed for a week, and purified water was replaced every two hours to remove impurities. Finally, the product was dried under $40^{\circ} \mathrm{C}$ vacuum for 2 days. After GO was dissolved in solvent, monolayer GO was prepared by ultrasonic dispersion method.

2.3. Preparation of SGO-PS. The synthetic process of SGO-PS was shown in Figure 1. Using a carboxyl group on a trithiocarbonate under the coupling of EDC and NHS, an esterifica- tion reaction with a hydroxyl group on $\mathrm{GO}$ was performed to obtain a macromolecular chain transfer agent-trithioestermodified GO (SGO). Firstly, $0.5 \mathrm{~g}$ of GO was placed in $50 \mathrm{~mL}$ of DMF solution, and after sonication for 1 hour, $0.5 \mathrm{~g}$ of EDC and NHS was put into the solution for half an hour of ultrasound. The trithioester was quantitatively added to the solution according to orthogonal Table 1 . After reacting at $80^{\circ} \mathrm{C}$ for 12 hours, it was taken out and filtered, and washed with chloroform three times to remove unreacted trithioester and coupling agent. The product was vacuum dried at $40^{\circ} \mathrm{C}$ to obtain a macromolecular chain transfer agent (SGO). Then, SGO, initiator (azobisisobutyronitrile), and styrene were added to the flask quantitatively according to orthogonal (Table 2). After adding $50 \mathrm{~mL}$ of DMF solution to fully ultrasonic for half an hour, the temperature was raised to the temperature set by an orthogonal design experiment (Table 2). The product was dissolved and washed with dichloromethane several times, and then the product (SGO-PS) was precipitated with a methanol solution. After several times of washing, the product was vacuum dried at $40^{\circ} \mathrm{C}$ for 24 hours.

2.4. Preparation of PLA/SGO-PS Nanocomposites. PLA $\left(M_{w}=100000 \mathrm{~g} \cdot \mathrm{mol}^{-1}\right)$ and SGO-PS were dried in a vacuum at $60^{\circ} \mathrm{C}$ for 24 hours to remove residual water. PLA was mixed with a certain amount of SGO-PS in a sealed bag and then manually added to a twin-screw extruder (HAAKE Mini Lab II, Thermo Fisher Scientific, USA, diameter $19 \mathrm{~mm}, L / D=25: 1$ ) to prepare PLA nanocomposite by molten intercalation. The processing temperature is set at $180^{\circ} \mathrm{C}$ (from the feeding area to the die head), and the screw speed is set at $30 \mathrm{rpm}$. The addition amounts of SGO-PS in PLA/SGO-PS nanocomposites were $0 \mathrm{wt} \%, 0.1 \mathrm{wt} \%$, $0.3 \mathrm{wt} \%, 0.5 \mathrm{wt} \%$, and $0.7 \mathrm{wt} \%$, respectively. The PLA/SGOPS nanocomposite was then fused and extruded for pelletizing and injection molding, finally named PLA0 (pure PLA), PLA1, PLA2, PLA3, and PLA4, respectively. Under the conditions of 800 bar of pressure, $200^{\circ} \mathrm{C}$ of feed barrel temperature, $60^{\circ} \mathrm{C}$ of mold temperature, and 10 seconds pressure holding time, PLA material was injected with injection equipment (Thermo Mini Jet Pro, Thermo Fisher Scientific, USA) and prepared for standard tensile test and standard impact test. 
TABLE 1: Factor level of the orthogonal experiment $\mathrm{L}_{9}\left(3^{4}\right)$ for the preparation of SGO-PS.

\begin{tabular}{lcccc}
\hline & & Factors & & \\
Level & $\mathrm{A} /$ reaction temperature $\left({ }^{\circ} \mathrm{C}\right)$ & $\mathrm{B} / \mathrm{CAT}:$ AIBN $(\mathrm{mmoL})$ & $\mathrm{C} /$ styrene $(\mathrm{mL})$ & $\mathrm{D} / \mathrm{reaction}$ time $(\mathrm{h})$ \\
\hline 1 & 70 & $0.05: 0.1$ & 5 & 8 \\
2 & 80 & $0.1: 0.2$ & 5 & 10 \\
3 & 60 & $0.15: 0.3$ & 8 & 12 \\
\hline
\end{tabular}

TABLE 2: Results obtained from the orthogonal experiment for preparation of SGO-PS.

\begin{tabular}{lccccc}
\hline \multirow{2}{*}{ Numbers } & \multicolumn{5}{c}{ Factors } \\
& $\mathrm{A}$ & $\mathrm{B}$ & $\mathrm{C}$ & $\mathrm{D}$ & Grafting rate (\%) \\
\hline 1 & 1 & 1 & 1 & 1 & 14.36 \\
2 & 1 & 2 & 2 & 2 & 47.79 \\
3 & 1 & 3 & 3 & 3 & 59.61 \\
4 & 2 & 1 & 2 & 3 & 43.30 \\
5 & 2 & 2 & 3 & 1 & 48.08 \\
6 & 2 & 3 & 1 & 2 & 57.91 \\
7 & 3 & 1 & 3 & 2 & 22.94 \\
8 & 3 & 2 & 1 & 3 & 31.29 \\
9 & 3 & 3 & 2 & 1 & 11.90 \\
K1 & 40.59 & 26.87 & 34.52 & 24.78 & \\
K2 & 49.76 & 42.39 & 34.33 & 42.88 & \\
K3 & 22.04 & 43.14 & 43.54 & 44.73 & \\
R & 27.72 & 16.27 & 9.21 & 19.95 & \\
\hline
\end{tabular}

Effects of factors on experimental results: $\mathrm{A}>\mathrm{D}>\mathrm{B}>\mathrm{C}$. Optimum conditions: A2D3B3C 3 .

\subsection{Characterization}

2.5.1. Thermogravimetric Analysis. Thermal gravimetric analysis (TGA) was performed on the SDT-Q600 gravimetric analyzer (USA). Each sample was heated at a rate of $10^{\circ} \mathrm{C} / \mathrm{min}$ (approximately $6-10 \mathrm{mg}$ ) in a nitrogen atmosphere $(100 \mathrm{~mL} / \mathrm{min})$ from room temperature to $600^{\circ} \mathrm{C}$.

Grafting rate $=[($ total mass of initial thermogravimetric sample - thermogravimetric residual mass)/total mass of initial thermogravimetric sample $] \times 100 \%$.

2.5.2. Fourier Transform Infrared Spectroscopy. The Fourier transform infrared spectrum (FTIR) of the sample was recorded on the Bruker-Equinox 55 spectrometer of Karlsruhe, Germany, using the standard $\mathrm{KBr}$ particle/disk technique. The spectra were recorded in the spectral range of $4000-400 \mathrm{~cm}^{-1}$ with a resolution of $4 \mathrm{~cm}^{-1}$. All samples were dried in a vacuum oven at $60^{\circ} \mathrm{C}$ for 24 hours for analysis.

2.5.3. Contact Angle Test. Using a contact Angle instrument (JJ2000B2, Zhongchen Digital Technology Co., Ltd., China) to determine the static contact angle of water on GO and SGO-PS surfaces. Before the test, the $0.3 \mathrm{~g}$ powder sample was put into a die with a radius of $10 \mathrm{~mm}$ and pressed into $2 \mathrm{~mm}$ thin sections under $10 \mathrm{MPa}$ pressure by the SSP-10 tablet press. When the water with a fixed volume of $0.2 \mathrm{~mL}$ drips on the sample for 2 seconds, the contact angle meter will automatically take a screenshot. Each sample was measured five times and the average contact angle of each sample was calculated using computational software.

2.5.4. X-Ray Photoelectron Spectroscopy. The chemical constituents of GO and SGO-PS were determined by X-ray photoelectron spectroscopy (XPS). The X-ray source is $\mathrm{Al} \mathrm{K} \alpha$, the voltage was $12 \mathrm{kV}$, and the current was $5 \mathrm{~mA}$. The pressure in the sample analysis chamber is less than $6.7 \times 10^{-7}$ Torr; the sample detection angle was $90^{\circ}$. All binding energies refer to the C1s hydrocarbon peak at $284.7 \mathrm{eV}$.

2.5.5. Transmission Electron Microscopy. The morphology of GO, SGO-PS, and PLA/SGO-PS were observed by transmission electron microscopy (TEM), TECNAI G2-F20 (FEI Co., the Netherlands). The sample was observed at an accelerating voltage of $75 \mathrm{kV}$. Before TEM detection, GO and SGO-PS were ultrasonic dispersed in the DMF for $30 \mathrm{~min}$. The ultrathin slice of PLA/SGO-PS nanocomposites samples was done by LEICA uc7 microtome, and the thickness of ultrathin slices was about $150 \mathrm{~nm}$.

2.5.6. Tensile Property Analysis. The mechanical performance test was completed on the CMT6104 electronic universal testing machine (Shenzhen New Sansi Measurement Technology Co., Ltd.). Stretching speed was $5 \mathrm{~mm} / \mathrm{min}$, in accordance with ASTM D 638 standard. At least five measurements were recorded for each sample.

2.5.7. Impact Strength Analysis. The notch impact test was carried out by the electronic impact testing machine (Chengde Jinjian Testing Instrument Co., Ltd.) according to the ASTM D256 standard. The sample size is $80 \mathrm{~mm} \times 10$ $\mathrm{mm} \times 4 \mathrm{~mm}$. For each sample, at least 5 data points are obtained and the average value is calculated.

2.5.8. SEM Analysis of Impact Section. A scanning electron microscope (SEM) with an acceleration voltage of $20 \mathrm{kV}$ was used to observe the morphology of PLA/SGO-PS nanocomposites. Before scanning electron microscopy analysis, a small amount of sample was intercepted and fixed on the stage with conductive adhesive, and placed in the sample processing tank for gold spraying treatment.

2.5.9. Differential Scanning Calorimeter Analysis. A DSC Q2000 differential scanning calorimeter (TA Instruments, USA) was used for differential scanning calorimetry (DSC) analysis of PLA0 and PLA2 samples (approximately 6$10 \mathrm{mg}$ ). The test was performed under a nitrogen atmosphere (50 $\mathrm{mL} / \mathrm{min})$. The sample was heated from room temperature to $200^{\circ} \mathrm{C}$ at a heating rate of $10^{\circ} \mathrm{C} / \mathrm{min}$, and the DSC 
curve of the process was recorded. The enthalpy and peak of the second heating curve were calculated by the TA universal analysis software [32].

2.5.10. Polarized Optical Microscopy Analysis. In order to study the spherical microstructure of PLA nanocomposites during isothermal crystallization, the crystal morphology of the samples was studied using polarized optical microscopy (POM). Place a small amount of sample on a glass slide and heat it to $200^{\circ} \mathrm{C}$ at a temperature increase rate of $50^{\circ} \mathrm{C} / \mathrm{min}$. After holding at a constant temperature for 3 minutes, the sample was quickly cooled to $130^{\circ} \mathrm{C}$ for isothermal crystallization. The isothermal crystalline form of the sample can be observed and photographed by a polarizing microscope.

2.5.11. Rheological Analysis. The pure PLA and PLA nanocomposite film samples were cut into $40 \mathrm{~mm} \times 400 \mathrm{~mm} \times$ $0.3 \mathrm{~mm}$ test blocks, and the linear viscoelastic behavior of PLA was studied with MARS60 rotary rheometer. Set the test temperature to $180^{\circ} \mathrm{C}$ and use a parallel plate fixture with a pitch set between $0.3 \mathrm{~mm}$ and $0.5 \mathrm{~mm}$. The strain is set to $2.1 \%$, and the PLA scan frequency range is $0.1 \mathrm{rad} / \mathrm{s}$ $100 \mathrm{rad} / \mathrm{s}$. All tests are performed after the temperature rises to the set temperature and stabilizes for 5 minutes. This step is to eliminate the influence of the thermal history of PLA on the rheological properties.

\section{Results and Discussion}

3.1. Optimization of SGO-PS Synthesis. In this work, the optimum conditions for the preparation of SGO-PS were determined by orthogonal design experiments. Since the weight loss rate of thermogravimetry caused by grafting poly (styrene) varies, it is regarded as the objective function of SGOPS. In addition, the reaction temperature, reaction time, molar ratio of chain transfer agent (CAT) to the initiator (AIBN), and styrene content were selected as the four main influencing factors of the orthogonal experiment. Through the orthogonal design experiment of $\mathrm{L}_{9}\left(3^{4}\right)$ (Table 1), the optimum process conditions were determined, and PLA/SGO-PS nanocomposites were prepared using SGOPS as a filler by melt intercalation method. Table 2 showed that the influence coefficients of SGO-PS synthesis were $27.72,16.27,9.21$, and 19.95, respectively, which indicated that the factor A (temperature) had the greatest effect on the synthesis of SGO-PS. The orthogonal test showed that the optimum reaction conditions were a reaction temperature of $80^{\circ} \mathrm{C}$, an optimum reaction time of 12 hours, a millimole ratio of chain transfer agent to initiator (AIBN) of $0.15: 0.3$, and a styrene volume of $8 \mathrm{~mL}$.

3.2. Thermogravimetric Analysis and Characterization of $S G O-P S$. Figure 2 showed the thermogravimetric curves of GO, SGO-PS samples (1-9), and SGO-PS samples prepared under the optimal reaction conditions. As shown in Figure 2, the mass loss temperature range of GO was $120^{\circ} \mathrm{C}-350^{\circ} \mathrm{C}$. The thermal weight loss at a temperature of $150^{\circ} \mathrm{C}$ was caused by the evaporation of water between GO layers. The mass loss at a temperature range of $150^{\circ} \mathrm{C}$ $350^{\circ} \mathrm{C}$ was due to the high temperature decomposition of

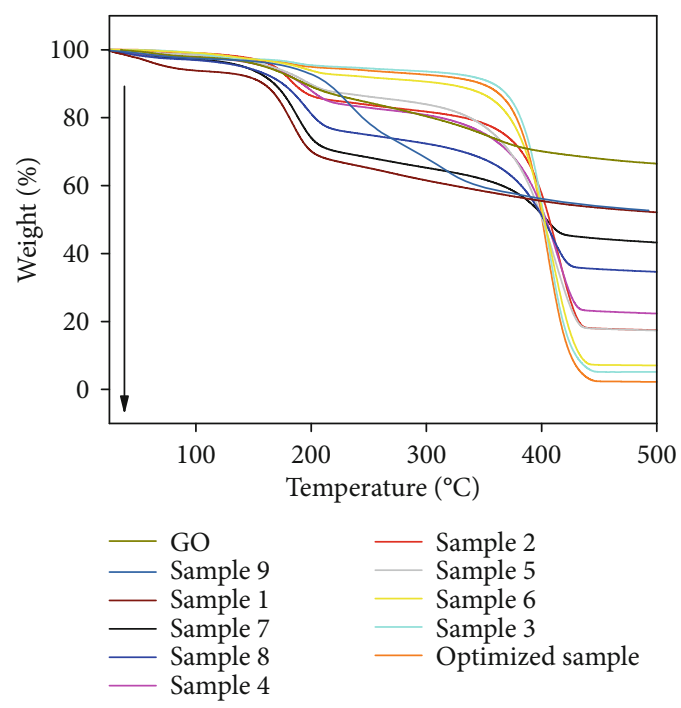

Figure 2: Thermogravimetric curves of GO, SGO-PS samples (1-9), and the optimum sample of SGO-PS.

oxygen-containing functional groups such as hydroxyl groups and carboxyl groups on the surface of the GO into $\mathrm{CO}, \mathrm{CO}_{2}$ and water vapor. The weight loss of the SGO-PS orthogonal experiment samples (1-9) mainly occurred at a temperature range of $395^{\circ} \mathrm{C}-450^{\circ} \mathrm{C}$, which was the mass loss caused by the decomposition of poly (styrene) grafted to SGO [33]. According to the best experimental conditions, the maximum grafting amount of poly (styrene) was $62.46 \%$. This result indicated that the poly (styrene) molecular chain was grafted onto the SGO surface.

As shown in Figure 3, the functional groups of SGO were analyzed by infrared. In the FTIR spectrum of GO, the peak appearing at $1712 \mathrm{~cm}^{-1}$ was $\mathrm{C}=\mathrm{O}$, and the peak appearing at $1617 \mathrm{~cm}^{-1}$ was $C=C$ [34]. In the SGO spectrum, $2922 \mathrm{~cm}^{-1}$ and $2855 \mathrm{~cm}^{-1}$ belong to the infrared vibration absorption peaks of $-\mathrm{CH}_{3}$ and $-\mathrm{CH}_{2}$, respectively. In the SGO infrared spectrum, the hydroxyl vibration peak at the $3406 \mathrm{~cm}^{-1}$ peak position becomes weaker and moves to a low wave number to $3386 \mathrm{~cm}^{-1}$. Moreover, the absorption vibration peaks of C-S and $\mathrm{S}=\mathrm{C}$ in $\mathrm{SGO}$ are at $1100 \mathrm{~cm}^{-1}$ and $1252 \mathrm{~cm}^{-1}$, which indicates that the synthesis of SGO is an esterification reaction process [35]. Figure 3(b) shows the FTIR spectra of SGOPS and PS. The peak positions at $3026 \mathrm{~cm}^{-1}, 2924 \mathrm{~cm}^{-1}$, and $2850 \mathrm{~cm}^{-1}$ are stretching vibration of the benzene ring $(=\mathrm{CH})$, asymmetric stretching vibration $\left(-\mathrm{CH}_{2}\right)$, and symmetrical stretching vibration $\left(-\mathrm{CH}_{2}\right)$. The peak positions at $1650 \mathrm{~cm}^{-1}, 1600 \mathrm{~cm}^{-1}$, and $1492 \mathrm{~cm}^{-1}$ are the $\mathrm{C}=\mathrm{C}$ stretching vibration and the $\mathrm{CH}=\mathrm{CH}$ - vibration peak position on the benzene ring. The peak at $757 \mathrm{~cm}^{-1}$ and $700 \mathrm{~cm}^{-1}$ are $=\mathrm{CH}$ out-of-plane deformation vibrations on monosubstituted benzene rings. The above main characteristic peaks indicate that SGO-PS has been synthesized.

The images of contact angles of water droplets on the surfaces of GO and SGO-PS were shown in Figures 3(a) and 3(b). The contact angle formed by liquid (water) on the surface of different samples was completely different. It can be seen from Figure 3 that the water contact angles of GO and SGO-PS were $12^{\circ}$ and $90^{\circ}$, respectively. This 


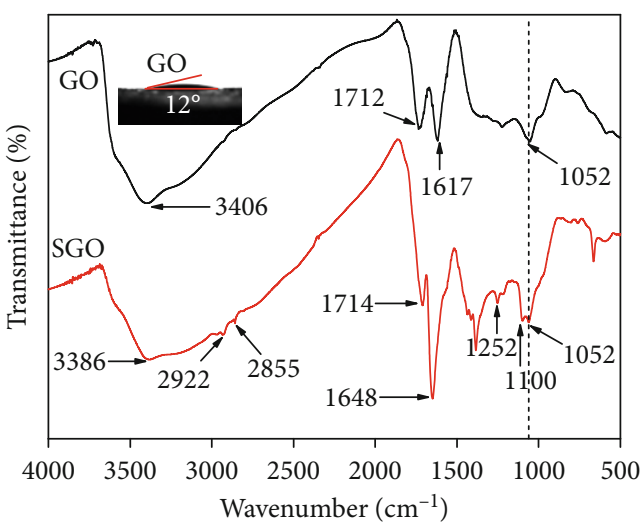

(a)

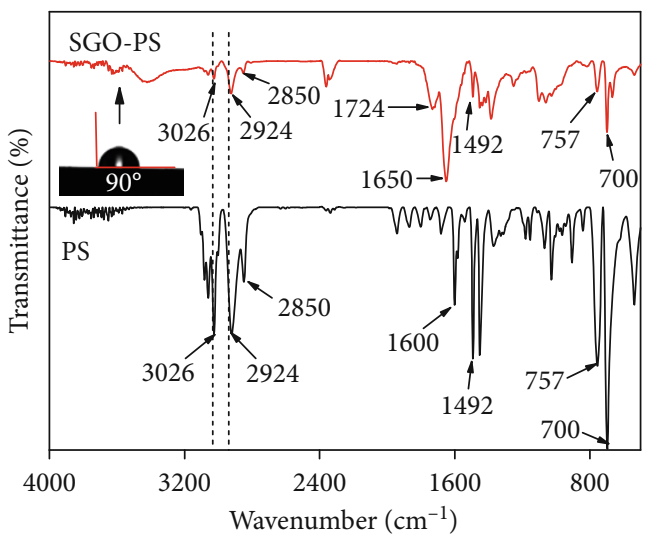

(b)

FIGURE 3: (a) FTIR spectra of GO and SGO; liquid (water) contact angle of the GO sample surface; (b) FTIR spectra of SGO-PS and PS samples; liquid (water) contact angle of the SGO-PS sample surface.

proved that the hydrophobicity of SGO was improved after the grafting reaction due to the introduction of a hydrophobic group (benzene ring). This result was also consistent with the FTIR analysis.

The XPS spectra of GO, SGO, and SGO-PS were shown in Figure 4, and the results were shown in Table 3. XPS provides quantitative information on elemental composition and chemical bonds in GO, SGO, and SGO-PS. The C/O atomic ratio in GO (60.04\%/39.49\%) indicated that graphene oxide had been prepared. As shown in Figure 4(d), the C1s peak in the XPS spectrum of SGO was divided into three peaks, including C-C (284.7 eV), C-O-C (286.9 eV), and O$\mathrm{C}=\mathrm{O}(288.8 \mathrm{eV})$. The content of these three groups in SGO was much higher than that of unmodified GO [36], which was due to the further increase of $\mathrm{C}-\mathrm{O}-\mathrm{C}$ and $\mathrm{O}-\mathrm{C}=\mathrm{O}$ content after modification with trithiocarbonate. As shown in Table 3, compared with pure GO, the C content of the SGO sample increased significantly, and the atomic ratio of $\mathrm{C} / \mathrm{O}$ increased from 1.52 to 2.33 , which was due to the increased carbon content of graphene oxide modified with trithiocarbonate. At the same time, after the graft modification of PS, the atomic ratio of $\mathrm{C} / \mathrm{O}$ was further increased to 11.42 , which proved that a large amount of polystyrene was grafted on the SGO surface. XPS results demonstrated that the hydroxyl group on the GO surface was esterified with the trithiocarbonate to generate the macromolecule chain transfer agent SGO and the graft product was generated by the RAFT polymerization method, which was consistent with the FTIR analysis.

3.3. TEM Analysis. In order to observe the microscopic morphology of GO, SGO-PS, and PLA/SGO-PS (0.3 wt\%), they were photographed by TEM. Figure 5 showed the TEM images of the above three kinds of samples. Figure 5 showed that both GO and SGO-PS nanoparticles had thin lamellar structures with slight folds, but it was obvious from Figure 5 that GO lamellar was thinner. It had been reported in the literature [37] that GO had a large specific surface area, with an average transverse size greater than $1 \mu \mathrm{m}$ and a thickness of about $2.8 \mathrm{~nm}+/-0.2 \mathrm{~nm}$. The lamellar surface of SGO-PS had polymer dark characteristic materials, indicat- ing that its thickness was relatively larger than that of GO [38], which intuitively indicated that a large amount of polystyrene had been grafted into the GO nanolayer and the surface of the nanolayer, resulting in increased nanolayer thickness. To reveal the dispersibility, compatibility, and intercalation degree of SGO-PS in the PLA matrix, PLA2 was investigated with TEM in this work. As shown in Figure 5(c), there was no obvious aggregation of SGO-PS particles. In addition, it was found that the soft and wrinkled sheet of SGO-PS was well dispersed in the PLA matrix, which indicated that SGO-PS was finally peeled off and evenly dispersed at the nanolevel. Furthermore, the edge of the SGOPS sheet in Figure 5(c) was soft and blurred from the initial sharp boundary, indicating that the graft product had better compatibility with the matrix PLA.

3.4. Analysis of Mechanical Properties of PLA/SGO-PS Nanocomposites. The effect of SGO-PS content on the mechanical properties of PLA/SGO-PS nanocomposites was shown in Figure 6. The tensile strength and impact strength of pure PLA were $76.78 \mathrm{MPa}$ and $10 \mathrm{KJ} / \mathrm{m}^{2}$, respectively. The mechanical properties of the PLA2 (PLA/SGO-PS $(0.3 \mathrm{wt} \%))$ nanocomposites reached a maximum value, with a tensile strength of $82.56 \mathrm{MPa}$ and impact strength of $17.50 \mathrm{KJ} / \mathrm{m}^{2}$. Thus, the increased impact strength confirmed the increased toughness of the PLA2 [39]. However, with the further increase of SGO-PS content, the mechanical properties of PLA nanocomposites gradually decreased [40]. A small amount of SGO-PS can be evenly dispersed in the PLA matrix and can be well embedded in the PLA matrix to make it have a strong intermolecular force and van der Waals force with the PLA matrix. When the content of SGO-PS was higher than $0.3 \mathrm{wt} \%$, the mechanical properties of PLA/SGO-PS nanocomposites decreased rapidly. This may be related to the decreased dispersion uniformity and anisotropy of SGO-PS in the matrix. Theoretically, a large number of SGO-PS nanoflakes accumulate at the two-phase interface through electrostatic interaction, and the interaction between them and the molecular chain of PLA matrix was weakened, resulting in the interruption of the matrix continuity of PLA nanocomposites, which led to the strict 


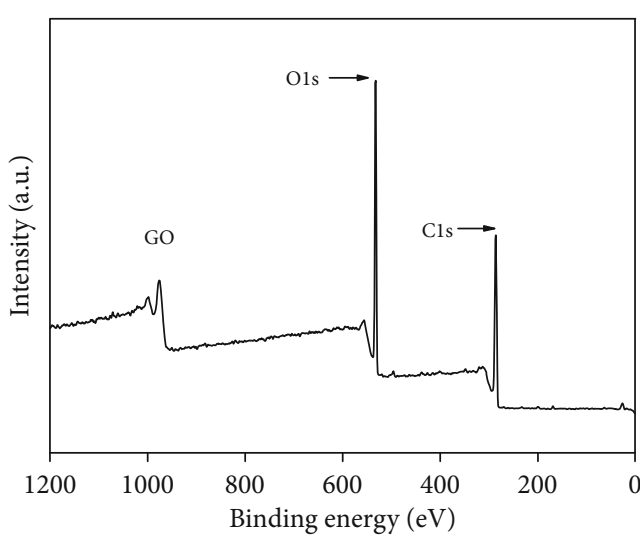

(a)

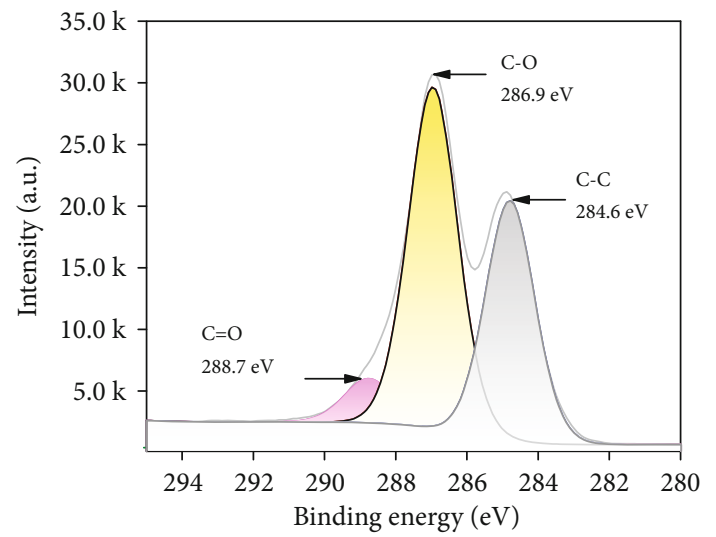

(c)

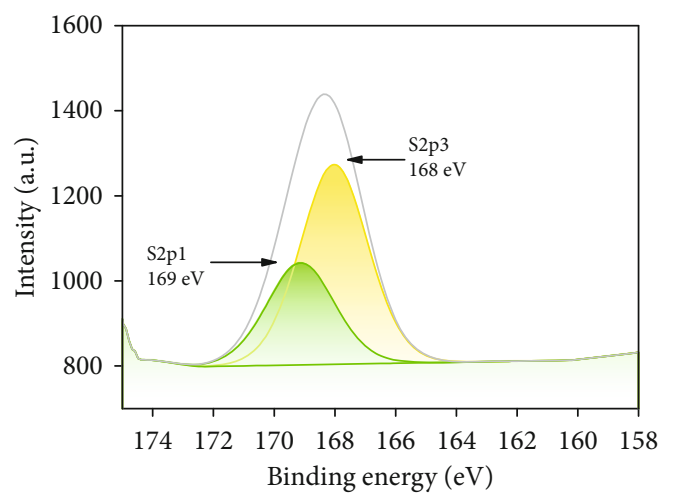

(e)

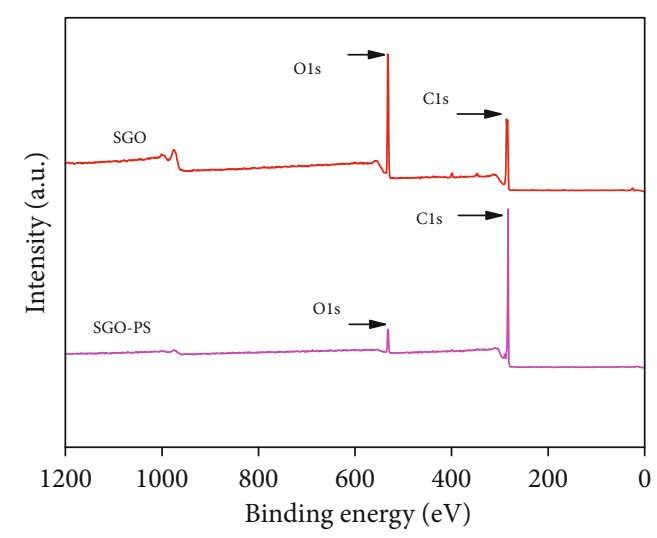

(b)

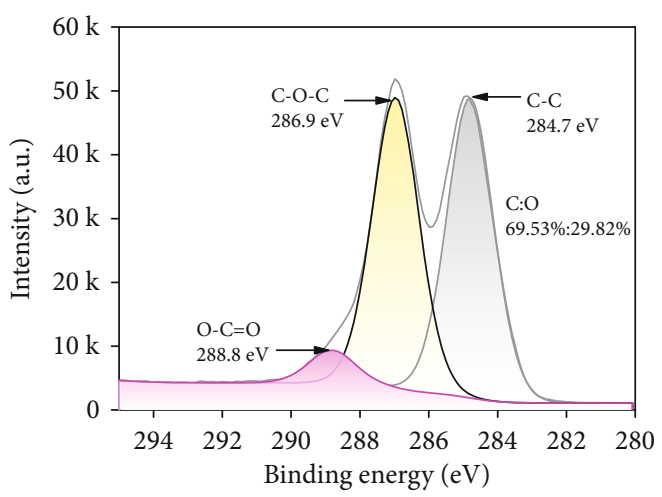

(d)

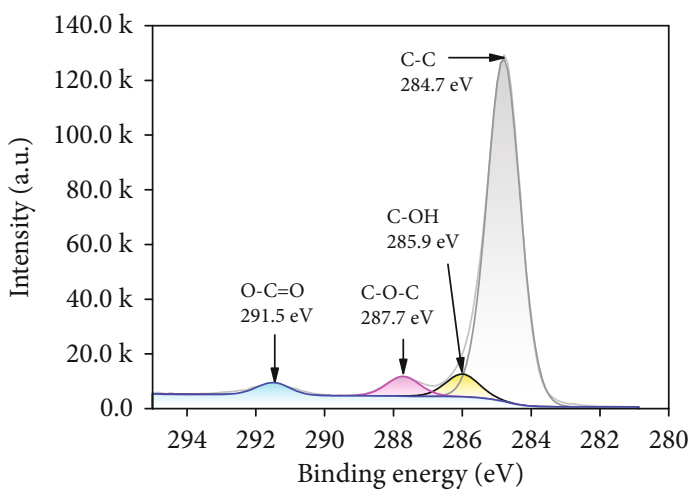

(f)

FIGURe 4: XPS analysis of GO, SGO, and SGO-PS (a) Full spectrum of GO; (b) Full spectrum of SGO and SGO-PS; (c) C1s spectrum of GO; (d) C1s spectrum of SGO; (e) S spectrum of SGO; (f) C1s spectrum of SGO-PS.

TABLE 3: The relative atomic percentage of GO, SGO, and SGO-PS.

\begin{tabular}{lccc}
\hline \multirow{2}{*}{ Sample } & \multicolumn{2}{c}{ Chemical } & Ratio of element \\
& Composition (\%) & C/O \\
\hline GO & 60.04 & 39.49 & 1.52 \\
SGO & 69.53 & 29.82 & 2.33 \\
SGO-PS & 91.95 & 8.05 & 11.42 \\
\hline
\end{tabular}

restrictions on the growth and movement of PLA molecular chain in space. When the material was subjected to external force, local stress concentration occurred, which ultimately reduced the mechanical properties of PLA nanocomposites.

The fracture surface morphology of PLA/SGO-PS nanocomposites and PLA was studied by SEM. Figure 6(b) showed the impact fracture surface morphology before and after the introduction of SGO-PS in the PLA matrix. As shown in Figure 6(b), the impact fracture surface of PLA0 was smooth, showing a typical brittle fracture, which was consistent with the low toughness and low impact strength 


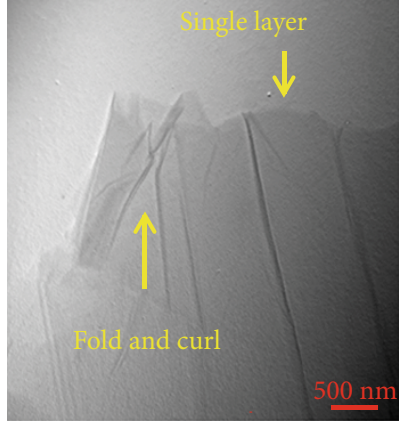

(a)

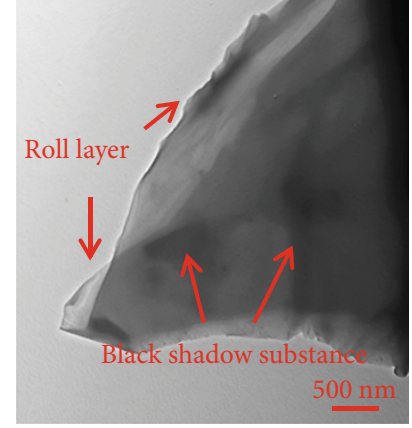

(b)

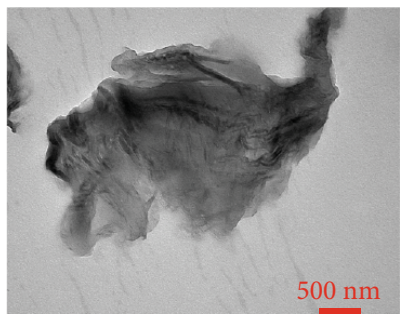

(c)

Figure 5: TEM images of GO, SGO-PS, PLA/SGO-PS (0.3 wt\%) (a) GO; (b) SGO-PS; (c) PLA/SGO-PS(0.3 wt\%).

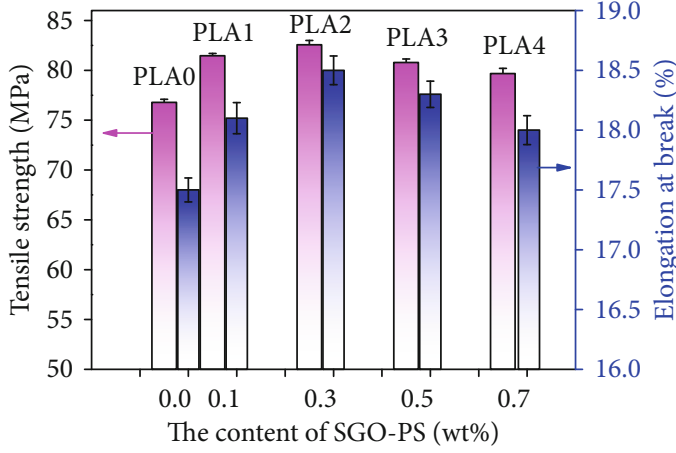

(a)

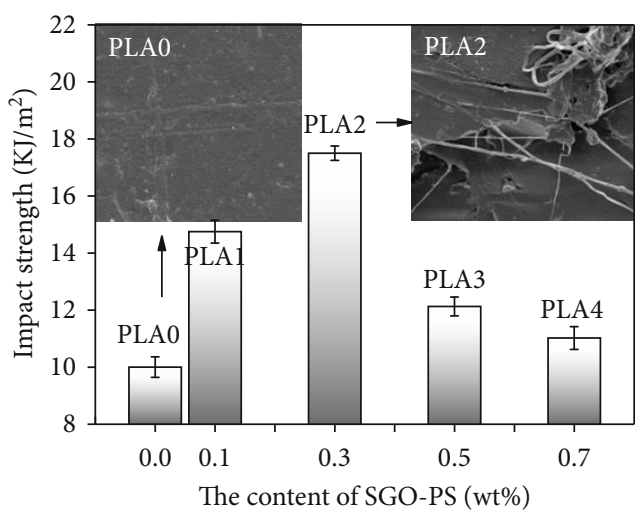

(b)

FIGURE 6: Effects of SGO-PS content on mechanical properties of PLA/SGO-PS nanocomposites (a) tensile strength and elongation at break; (b) impact strength and impact fracture SEM images of PLA0 and PLA2.

of PLA. However, the fracture surface of PLA2 had an oriented fiber tough wire, which showed the characteristics of ductile fracture [7]. These results confirmed that SGO-PS had a strong toughening effect on PLA, thus changing its fracture characteristics from brittle fracture to ductile fracture. When PLA based nanocomposites were impacted, this oriented tough wire structure can absorb more impact energy, which helped to improve the toughness and plastic deformation during mechanical testing. The results showed that the introduction of SGO-PS helped to improve the comprehensive performance of PLA.

3.5. TGA Analysis. Figure 7 showed the thermal stability of PLA0 and PLA2 nanocomposites as determined by TGA. The maximum thermal decomposition rate temperature
$\left(T_{\max }\right)$, thermal decomposition onset temperature ( $\left.T_{\text {onset }}\right)$, and final decomposition temperature $\left(T_{\text {end }}\right)$ of PLA0 and PLA2 were shown in Figure 7. Compared with PLA0, the $T_{\text {on- }}$ set and $T_{\max }$ values of PLA2 were increased by $8^{\circ} \mathrm{C}$ and $5^{\circ} \mathrm{C}$, respectively. This showed that the introduction of SGO-PS nanoparticles had improved the heat resistance of PLA2 nanocomposites to some extent compared with PLA0. This was due to SGO-PS as heterogeneous nucleation sites uniformly dispersed in the PLA matrix, which increased the degree of crystallinity, all the heat energy required for decomposition barriers had been increased [7]. Secondly, the added SGO-PS and the PLA molecules in the composite material formed a spatial network structure, which limited the activity of the PLA molecular chain and the thermal movement of the molecule, which undoubtedly enhanced its binding force 


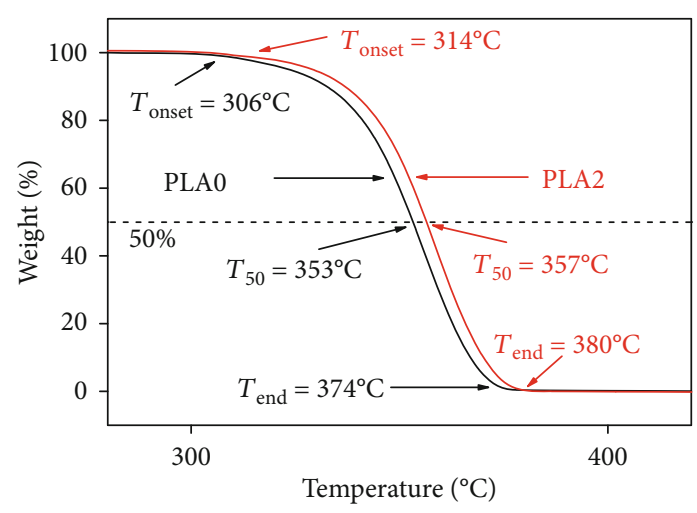

(a)

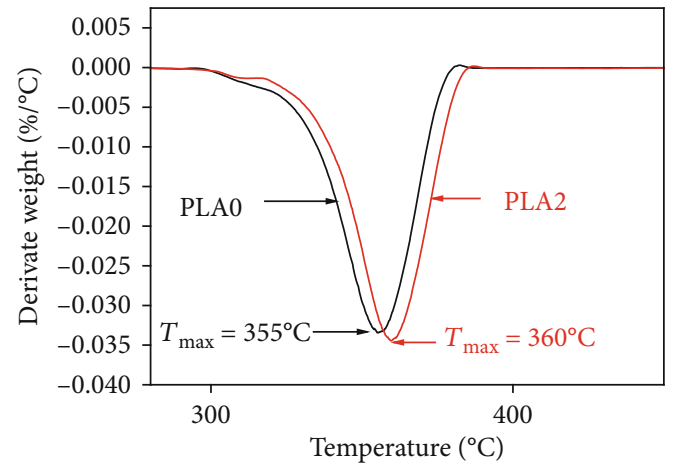

(b)

Figure 7: TGA curves for PLA0 and PLA2 (a) TG curves; (b) DTG curves.

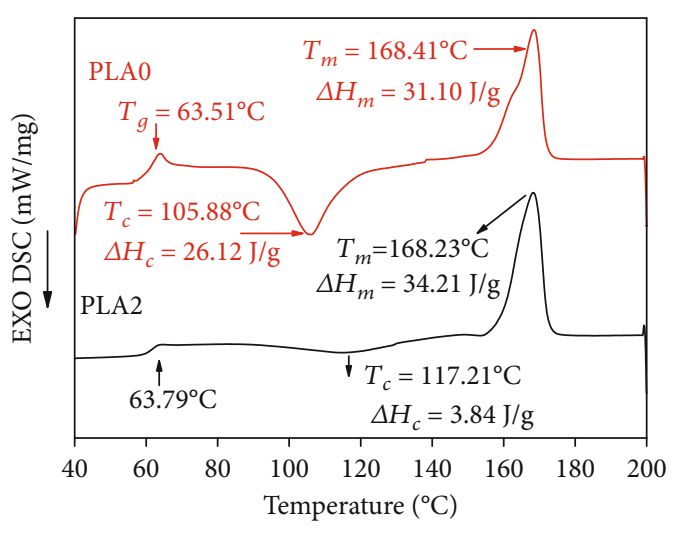

FIGURE 8: DSC curves of PLA0 and PLA2.

with the PLA molecular chain. This result was consistent with the mechanical properties testing of PLA/SGO-PS.

3.6. Crystallization Property and Multiple Melting Behavior of PLA Nanocomposites. The DSC curves of PLA0 and PLA2 nanocomposites were shown in Figure 8. The melting temperature $\left(T_{m}\right)$, cold crystallization enthalpy $\left(\Delta H_{c}\right)$, melting enthalpy $\left(\Delta H_{m}\right)$, and crystallinity $\left(X_{c}\right)$ can be obtained from Figure 8 . The formula for calculating the crystallinity of PLA nanocomposites was as follows:

$$
X_{c}=\left[\left(\Delta H_{m}-\Delta H_{c}\right) /\left(f \times \Delta H_{m}^{\theta}\right) \times 100 \%\right]
$$

$\Delta H_{m}^{\theta}$ was the melting enthalpy when the crystallinity of the polymer material was $100 \%$ [41]. The $\Delta H_{m}^{\theta}$ of pure PLA is $93.7 \mathrm{~J} / \mathrm{g}$ [42], and $f$ is the mass fraction of pure PLA. The data in Figure 8 showed that the $T_{m}$ values of PLA0 and PLA2 were $168.41^{\circ} \mathrm{C}$ and $168.23^{\circ} \mathrm{C}$, respectively. In addition, it could be seen from Figure 8 that the cold crystallization peak of PLA2 obviously weakened after adding SGO-PS. It can be seen that the introduction of SGO-PS significantly reduced the cold crystallization enthalpy of PLA2. This indirectly indicated that the crystallization rate of PLA2 accelerated during the cooling stage, leading to the weakening or even complete disappearance of molecular chain rearrangement during the heating stage. In addition, from the crystallinity formula, the $X_{c}$ of PLA0 was $5.31 \%$, while the $X_{c}$ of PLA2 was $32.51 \%$, which was an increase of $27.2 \%$ compared to PLA0. This was because FGO played a role of heterogeneous nucleation in the PLA matrix, which increased the crystallinity of the PLA material. The above results showed that the addition of SGO-PS significantly improved the crystallization properties of PLA materials.

Figure 9 were polarized microscope images of PLA0 and PLA2. Figure 9 clearly showed that PLA0 had a typical spherulite structure. Under the same conditions, the nucleation density and the number of crystal nuclei of PLA2 increased significantly. Compared with PLA0 material, the spherulites of PLA2 were obviously refined, which indicated that the introduction of SGO-PS had accelerated the crystallization rate of PLA composites. Therefore, the growth of spherulites was hindered by the growth of adjacent spherulites, which made the size of spherulites smaller and significantly improved the crystallinity of PLA composites [43].

In addition, Figure 10 showed the spherulite radius size of PLA0 and PLA2 as a function of time during $130^{\circ} \mathrm{C}$ isothermal crystallization. It could be seen from the graph that the spherulite radius of PLA0 and PLA2 increased proportionally with time, and the growth rate $(G)$ of the spherulite could be calculated from the slope of the straight line in the figure. Through data fitting processing, the spherulite growth rates of PLA0 and PLA2 were $2.65 \mu \mathrm{m} / \mathrm{min}$ and $0.46 \mu \mathrm{m} / \mathrm{min}$, respectively. This was because the introduced SGO-PS provided a large number of crystal nuclei for the PLA matrix to induce a rapid crystallization rate, reduced the nucleation activation energy of PLA, and refined the spherulites. In a certain space, with the introduction of SGO-PS, the number of crystallites increased, the collision and accumulation of spherulites limited the growth of spherulites, thereby greatly increasing the nucleation density of PLA [44]. This result was consistent with the DSC result.

The crystallization of PLA was divided into two types of crystallization processes: isothermal crystallization and nonisothermal crystallization. And the crystalline melting curve can better reflect the crystallization history of PLA. Therefore, in order to provide a complete theoretical study of 


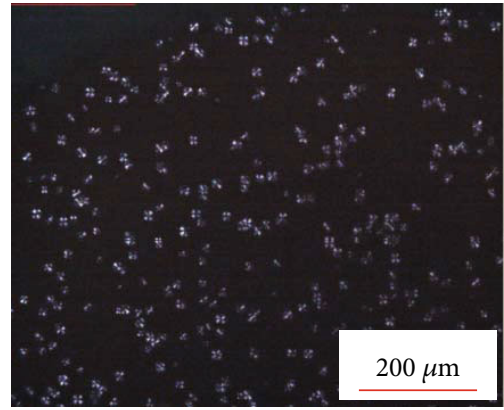

(a)

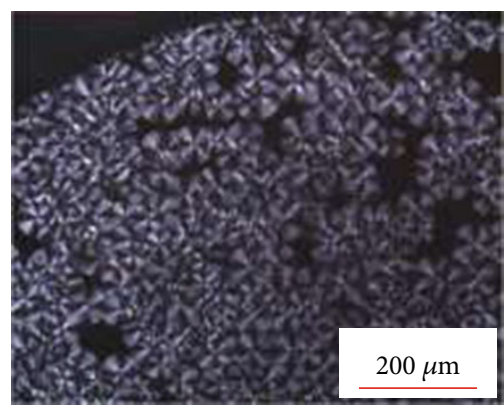

(c)

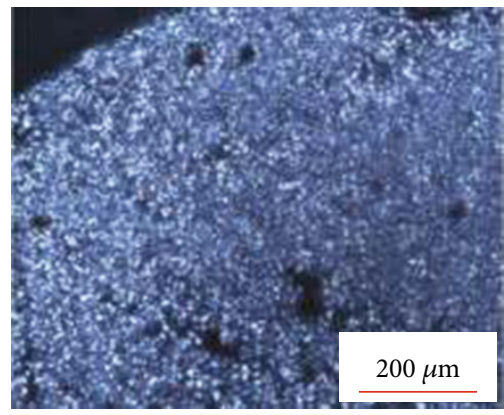

(e)

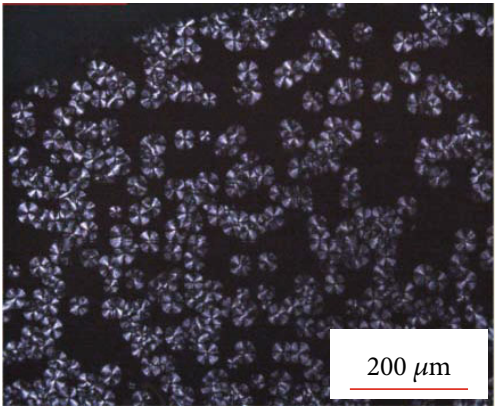

(b)

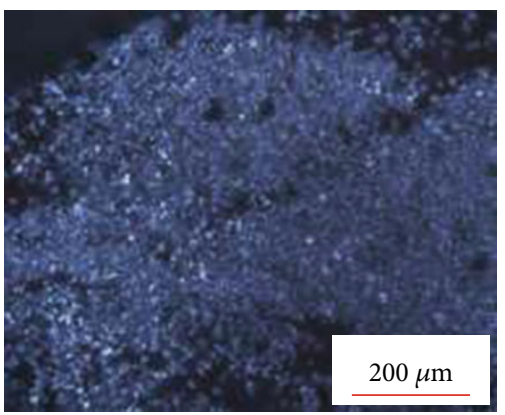

(d)

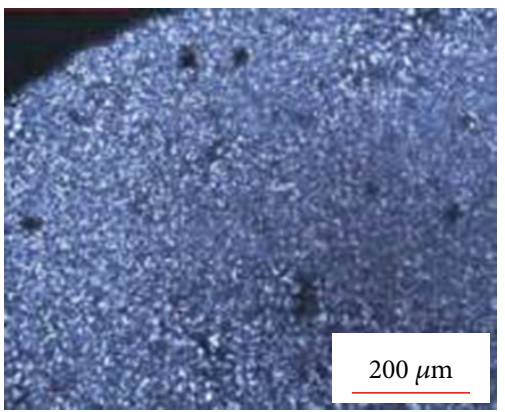

(f)

FIgURE 9: Evolution of the morphology of PLA0 and PLA2 over time under polarized optical microscopy morphology (a) PLA0 (5 min); (b) PLA0 (10 min); (c) PLA0 (15 min); (d) PLA2 (5 min); (e) PLA2 (10 min); (f) PLA2 (15 min).

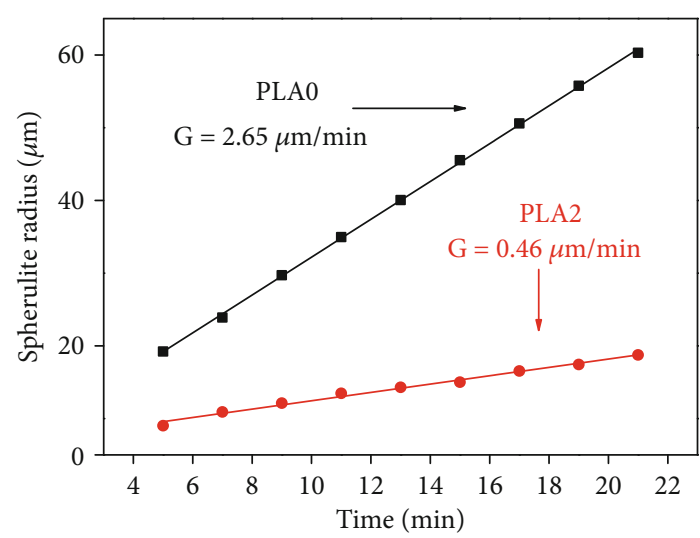

FIGURE 10: The spherulite radius changes of PLA0 and PLA2 with time during the isothermal crystallization at $130^{\circ} \mathrm{C}$. further crystallization after PLA molding, this experiment used DSC to study the melting behavior of PLA after isothermal crystallization at different temperatures for a certain period of time. When the melt of PLA was crystallized isothermally, it was easier to crystallize by setting its isothermal crystallization temperature $\left(T_{c}\right)$ at $90^{\circ} \mathrm{C}$ to $120^{\circ} \mathrm{C}$, and its crystallization time is shorter. Therefore, in this experiment, PLA0 and PLA2 were isothermally crystallized for 1 hour at the following four different temperatures $\left(90^{\circ} \mathrm{C}, 100^{\circ} \mathrm{C}\right.$, $110^{\circ} \mathrm{C}$, and $120^{\circ} \mathrm{C}$ ). The melting curves of the DSC heating process were then measured at the same heating rate $\left(10^{\circ} \mathrm{C} / \mathrm{min}\right)[45]$.

The melting curves of PLA0 and PLA2 after isothermal crystallization at different temperatures are shown in Figure 11. Table 4 showed the melting enthalpy values $\left(\Delta H_{M 1}, \Delta H_{M 2}\right)$ and cold crystallization enthalpy values $\left(\Delta H_{C}\right)$ of PLA0 and PLA2 at different isothermal crystallization temperatures. It can be observed from Figure 11 that when the isothermal crystallization temperature was $90^{\circ} \mathrm{C}$, 


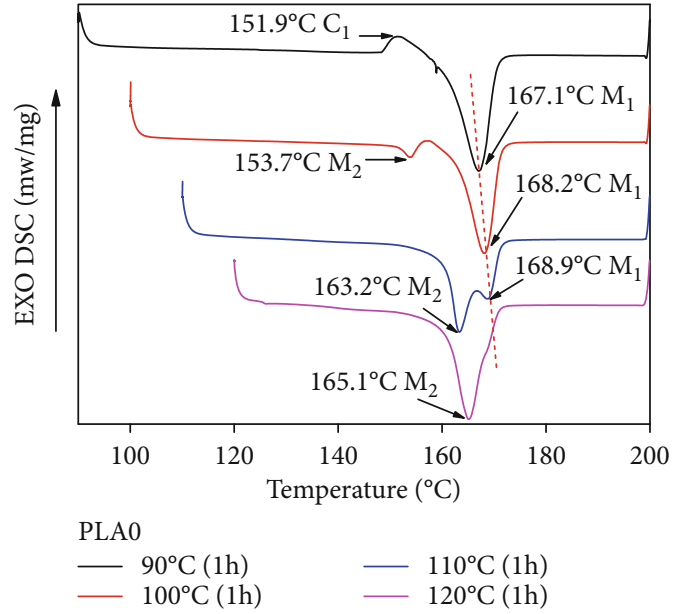

(a)

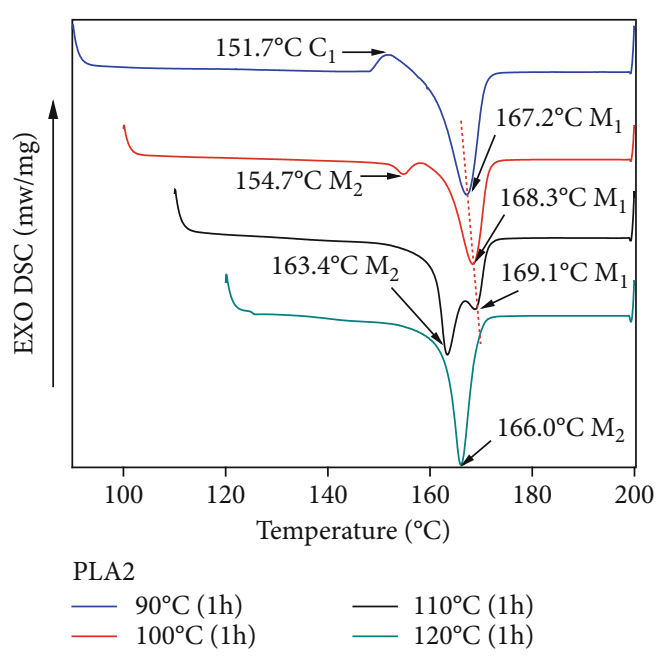

(b)

FIgure 11: The melting curves of PLA0 and PLA2 after different isothermal crystallization temperature (a) PLA0; (b) PLA2.

TABLE 4: $M_{1}$ and $M_{2}$ of PLA0 and PLA2 after different isothermal crystallization temperatures.

\begin{tabular}{lcccccc}
\hline Isothermal crystallization temperature $/\left({ }^{\circ} \mathrm{C}\right)$ & $\Delta H_{C 0} /(\mathrm{J} / \mathrm{g})$ & $\Delta H_{M 1} /(\mathrm{J} / \mathrm{g})$ & $\Delta H_{M 2} /(\mathrm{J} / \mathrm{g})$ & $\Delta H_{C 2} /(\mathrm{J} / \mathrm{g})$ & $\Delta H_{M 1} /(\mathrm{J} / \mathrm{g})$ & $\Delta H_{M 2} /(\mathrm{J} / \mathrm{g})$ \\
\hline 90 & 4.27 & 35.71 & 0 & 3.92 & 37.76 & 0 \\
100 & 0 & 32.38 & 2.97 & 0 & 26.99 \\
110 & 0 & 2.79 & 10.24 & 0 & 2.62 & 13.11 \\
120 & 0 & 0 & 39.63 & 0 & 0 \\
\hline
\end{tabular}

both the melting peak $M 1$ and a more obvious exothermic peak $C$ appeared in PLA0 and PLA2. This was because when the isothermal crystallization temperature was $90^{\circ} \mathrm{C}$, the insufficient vitality of the PLA molecular chain made it impossible for a part of the PLA molecular chain to be fully arranged into the lattice during the one-hour isothermal crystallization stage. However, as the temperature continued to rise, the chains of PLA molecules not previously arranged in the lattice would directly arrange into the lattice. This recrystallization rearrangement led to a large amount of energy release, so the heat absorption energy of the melt was much less than the exothermic heat of the recrystallization of the PLA molecule chain at this time, so the exothermic peak appeared on the melting curve. It could also be observed from the data that the exothermic peak enthalpy $\Delta H_{C}$ of PLA2 and PLA0 were $3.92 \mathrm{~J} / \mathrm{g}$ and $4.27 \mathrm{~J} / \mathrm{g}$, respectively. This showed that PLA0 had a greater number of recrystallizations during secondary crystallization, and that the molecular chain of PLA2 in the isothermal crystallization stage at $90^{\circ} \mathrm{C}$ was more than PLA0, which indicated that the crystallization performance of PLA2 at this temperature was higher than that of PLA0. When the temperature was $167.1^{\circ} \mathrm{C}$, the unit cell formed by the secondary crystallization of PLA started to melt and absorb heat, so the melting peak $M 1$ appeared. It could be seen from Table 4 that the $\Delta H_{M 1}$ of PLA0 and PLA2 were $35.71 \mathrm{~J} / \mathrm{g}$ and $37.76 \mathrm{~J} / \mathrm{g}$, respectively. The melting enthalpy of PLA2 was greater than PLA0, so it could be explained that the degree of crystallization of PLA2 was higher than that of PLA0.

When the isothermal crystallization temperature continued to rise to $100^{\circ} \mathrm{C}$, the exothermic peak $C$ disappeared, and a second melting peak $M 2$ appeared. This could be explained that in the process of isothermal crystallization at $100^{\circ} \mathrm{C}$ for 1 hour, the PLA molecular chain had more opportunities to get the energy to discharge into the crystal lattice, which resulted in a decrease in the number of PLA molecular chains that were not aligned in the crystal lattice, so the exotherm of recrystallization was reduced (exothermic peak $C$ disappeared). Therefore, when the heat absorption of melting increased and was much larger than the heat release of crystal rearrangement, the melting peak $M 2$ appeared in the figure. Compare the $\Delta H_{M 2}$ in Table 4 numerical, the $\Delta H_{M 2}$ value of PLA0 and PLA2 were $2.97 \mathrm{~J} / \mathrm{g}$ and $3.20 \mathrm{~J} / \mathrm{g}$, which indicated that the rearrangement of PLA2 exothermic less than PLA0. This indicated that the crystallization rate of PLA2 was faster than that of PLA0 at the $100^{\circ} \mathrm{C}$ isothermal crystallization stage. At the same time, the $\Delta H_{M 1}$ value of PLA0 decreased from $35.71 \mathrm{~J} / \mathrm{g}$ to $32.38 \mathrm{~J} / \mathrm{g}$; the $\Delta H_{M 1}$ value of PLA2 decreased from $37.76 \mathrm{~J} / \mathrm{g}$ to $26.99 \mathrm{~J} / \mathrm{g}$. It could be seen that the $\Delta H_{M 1}$ value of PLA2 was lower than PLA0. $\Delta H_{M 1}$ value change could be explained by the following reasons. The structure of isothermal crystal was less perfect and unstable at lower temperature. However, in the process of heating up, such imperfect cells will absorb energy and melt, and then 


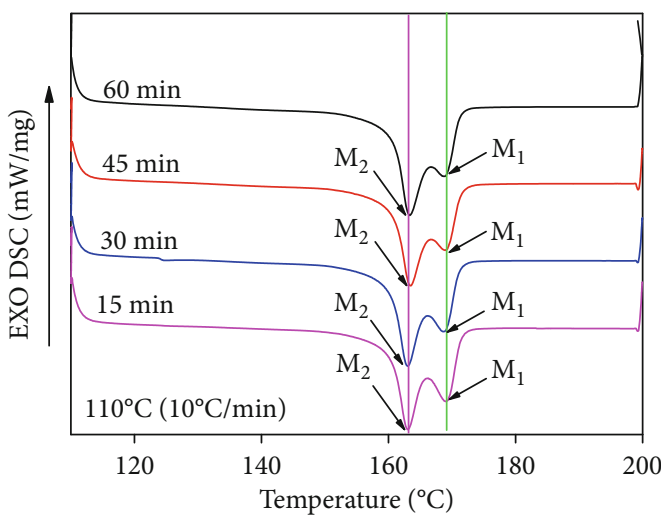

(a)

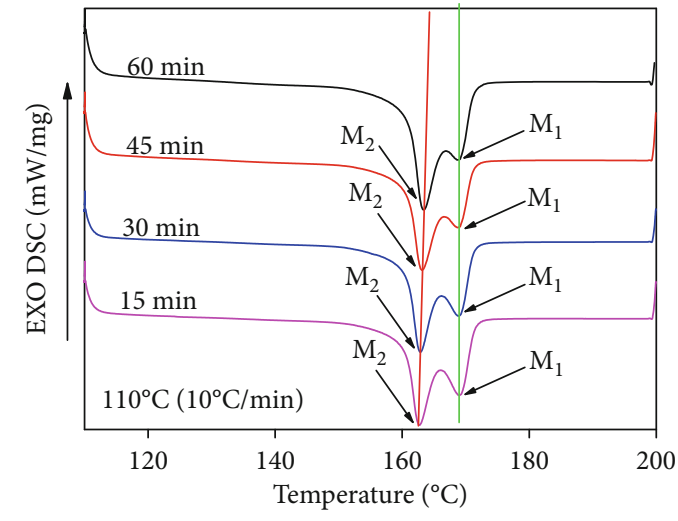

(b)

FIgURe 12: The effect of isothermal crystallization time of PLA0 and PLA2 on melting behavior (a) PLA0; (b)PLA2.

TABLE 5: Enthalpy and temperature of PLA0 and PLA2 at different isothermal crystallization time.

\begin{tabular}{|c|c|c|c|c|c|c|c|c|c|c|}
\hline \multirow{2}{*}{$\begin{array}{l}\text { Isothermal } \\
\text { crystallization } \\
\text { time/(min) }\end{array}$} & \multicolumn{5}{|c|}{ PLA0 } & \multicolumn{5}{|c|}{ PLA2 } \\
\hline & $\Delta H_{M 1} /(\mathrm{J} / \mathrm{g})$ & $\Delta H_{M 2} /(\mathrm{J} / \mathrm{g})$ & $\Delta H_{M 2} / \Delta H_{M 1}$ & $M 1 /\left({ }^{\circ} \mathrm{C}\right)$ & $M 2 /\left({ }^{\circ} \mathrm{C}\right)$ & $\Delta H_{M 1} /(\mathrm{J} / \mathrm{g})$ & $\Delta H_{M 2} /(\mathrm{J} / \mathrm{g})$ & $\Delta H_{M 2} / \Delta H_{M 1}$ & $M 1 /\left({ }^{\circ} \mathrm{C}\right)$ & $M 2 /\left({ }^{\circ} \mathrm{C}\right)$ \\
\hline 15 & 3.20 & 6.74 & 2.10 & 168.92 & 163.00 & 3.14 & 6.81 & 2.16 & 169.09 & 162.51 \\
\hline 30 & 3.12 & 6.81 & 2.18 & 168.90 & 163.1 & 3.04 & 6.89 & 2.26 & 169.09 & 162.83 \\
\hline 45 & 2.92 & 6.86 & 2.35 & 168.68 & 163.17 & 2.90 & 7.10 & 2.45 & 169.09 & 163.00 \\
\hline 60 & 2.74 & 7.14 & 2.60 & 168.60 & 163.18 & 2.65 & 7.13 & 2.69 & 168.92 & 163.49 \\
\hline
\end{tabular}

they will release heat for secondary crystallization to form more perfect cells. The $\Delta H_{M 1}$ value of PLA2 was slightly lower than PLA0, which meant that the introduction of SGO-PS could obviously improve the grain structure of PLA, weaken the rearrangement phenomenon during melting, and reduce the $\Delta H_{M 1}$ value. At the same time, the melting temperature shifted to a high-temperature direction, and the melting temperature lag occurred. As shown in the figure, M1 of PLA0 moved from $167.1^{\circ} \mathrm{C}\left(T_{C}=90^{\circ} \mathrm{C}\right)$ to $168.2^{\circ} \mathrm{C}$ $\left(T_{C}=100^{\circ} \mathrm{C}\right) ; M 1$ of PLA2 moved from $167.2^{\circ} \mathrm{C}\left(T_{C}=90^{\circ} \mathrm{C}\right)$ to $168.3^{\circ} \mathrm{C}\left(T_{C}=100^{\circ} \mathrm{C}\right)$. From the above data, it could be seen that the melting peak temperature of PLA2 was higher than PLA0, which also confirmed that its grain structure was more complete than that of PLA0, so the melting temperature will be shifted to higher temperature.

When the isothermal crystallization temperature rises to $110^{\circ} \mathrm{C}$, the degree of crystallization completeness of the unit cell at this temperature was higher than that at $100^{\circ} \mathrm{C}$. During the process of heating up, less rearrangement and exothermic heat will be generated, so the $\Delta H_{M 2}$ of the cell would be increased. The reason why the $\Delta H_{M 1}\left(T_{C}=110^{\circ} \mathrm{C}\right)$ became smaller was that the cell structure of PLA was more perfect in isothermal crystallization at higher temperature, and the melting heat absorption of the imperfect cells became less in the heating stage, which led to the decrease of $\Delta H_{M 1}$. It could be seen from Table 4 that the $\Delta H_{M 1}$ of PLA2 was smaller than that of PLA0, which indicated that the crystallization degree of PLA2 was higher than that of PLA0 at $110^{\circ} \mathrm{C}$. Moreover, as shown in the figure, the $M 1$ of PLA0 was moved from $168.2^{\circ} \mathrm{C}\left(T_{C}=100^{\circ} \mathrm{C}\right)$ to $168.9^{\circ} \mathrm{C}\left(T_{C}=110^{\circ} \mathrm{C}\right)$. The $M 1$ of the PLA2 was moved from $168.3^{\circ} \mathrm{C}\left(T_{C}=100^{\circ} \mathrm{C}\right)$ to $169.1^{\circ} \mathrm{C}\left(T_{C}=110^{\circ} \mathrm{C}\right)$. The melting temperature of PLA2 was also skewed towards higher temperatures than that of PLA0 because the imperfect cells generated at $110^{\circ} \mathrm{C}$ were more complete and stable than those generated at $T_{C}=10$ $0^{\circ} \mathrm{C}$. More heat melting was required for the more perfect cell, which led to the melting temperature shifting to high temperature. This result directly indicated that the crystallization performance of PLA2 was higher than that of unmodified PLA0.

When $T_{C}=120^{\circ} \mathrm{C}$, the PLA crystal became more and more perfect, and the crystallinity gradually increased. There were fewer molecules not included in the cell and fewer imperfect cells, resulting in the disappearance of $M 1$ in the heating process and the migration of $M 2$ to high temperature. The $M 2$ of PLA2 and PLA 0 moved to $166.0^{\circ} \mathrm{C}$ and $165.1^{\circ} \mathrm{C}$, respectively, indicating that the introduction of SGO-PS led to the increase of the crystal nuclei of PLA2, and the structure and stability of its crystal cells were better than that of PLA0 [45].

In the above results, the melting peak changes most obviously at $T_{C}=110^{\circ} \mathrm{C}$. The following experiments had tested and analyzed the effects of different isothermal crystallization times on the melting behavior differences between PLA0 and PLA2 at this temperature [46]. Figure 12 showed the melting enthalpy of PLA0 and PLA2 changing with different times at $110^{\circ} \mathrm{C}$ isothermal crystallization. Table 5 showed the enthalpy and temperature of PLA0 and PLA2 at different isothermal crystallization times. The heating rates of the experiments were all $10^{\circ} \mathrm{C} / \mathrm{min}$.

It could be observed from Figure 12 that under different isothermal crystallization time (15 min; $30 \mathrm{~min} ; 45 \mathrm{~min}$; and 


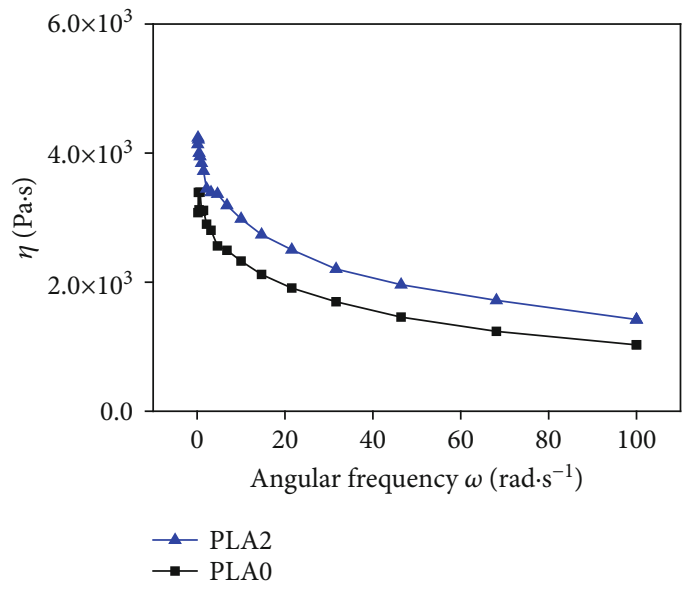

(a)

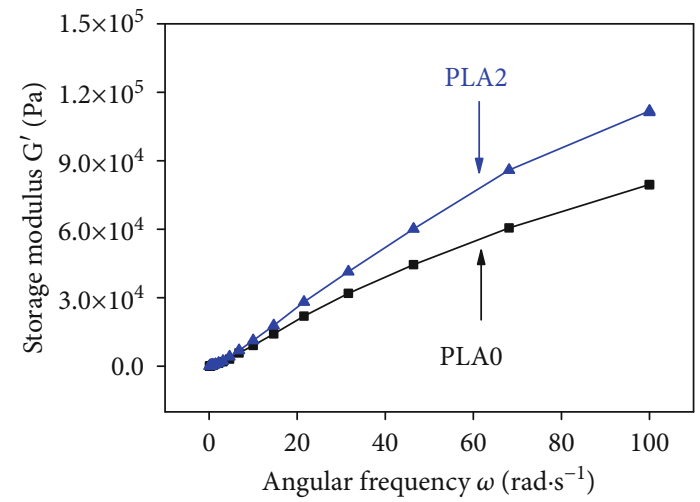

(b)

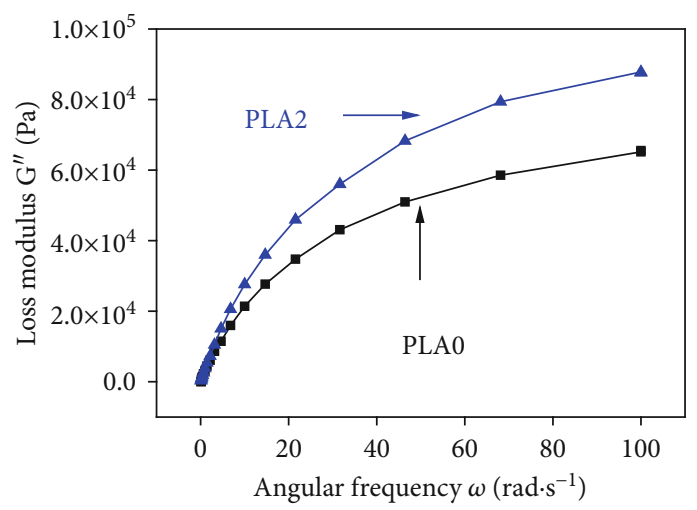

(c)

FIGURE 13: Rheological behavior of PLA0 and PLA2: (a) complex viscosity versus angular frequency; (b) the storage modulus versus angular frequency; (c) the loss modulus versus angular frequency.

$60 \mathrm{~min}$ ), two melting peaks ( $M 1$ and $M 2$ ) conforming to the characteristics of semicrystalline polymer were found. As the isothermal time gradually extended, the $\Delta H_{M 1}$ of PLA0 decreased from $3.20 \mathrm{~J} / \mathrm{g}$ to $2.74 \mathrm{~J} / \mathrm{g}$; the $\Delta H_{M 1}$ of PLA2 decreased from $3.14 \mathrm{~J} / \mathrm{g}$ to $2.65 \mathrm{~J} / \mathrm{g}$. And the $\Delta H_{M 2}$ of PLA0 gradually increased from $6.74 \mathrm{~J} / \mathrm{g}$ to $7.14 \mathrm{~J} / \mathrm{g}$; the $\Delta H_{M 2}$ of PLA2 gradually increased from $6.81 \mathrm{~J} / \mathrm{g}$ to $7.13 \mathrm{~J} / \mathrm{g}$. The $\Delta H_{M 2} / \Delta H_{M 1}$ of PLA0 gradually increased from 2.10 to 2.60 , the $\Delta H_{M 2} / \Delta H_{M 1}$ of PLA2 gradually increased from 2.16 to 2.69. The $\Delta H_{M 2} / \Delta H_{M 1}$ value of PLA2 slightly higher than the PLA0 can be explained as follows. During the isothermal crystallization of PLA, the stunted cells will release some heat due to the recrystallization process (i.e., secondary crystallization) during the heating process, and the melting peak at the high-temperature side was the melting peak $M 1$ of the more stable grain of the secondary crystallization. This process will cause the temperature of the melting peak $M 1$ to lag (that is, to the high-temperature migration). However, the relatively perfect crystal cell absorbed heat and melts during the heating process to produce the melting peak M2. With the extension of isothermal crystallization time, the number of normally developed cells gradually increased, making $M 2$ continuously increase and $M 1$ gradually decrease. In addition, the introduction of SGO-PS would make the underdeveloped grains tend to perfect during the crystallization process, thereby reducing the secondary crystallization melting peak enthalpy value $\Delta H_{M 1}$, resulting in the $\Delta H_{M 2} / \Delta H_{M 1}$ ratio of PLA2 greater than that of pure PLA with relatively incomplete crystal form. Therefore, SGO-PS can accelerate crystallization, shorten the crystallization period, and improve crystallinity in matrix PLA, which was consistent with the above POM and DSC test results [46].

3.7. Analysis of Rheological Properties of Modified PLA. Figure 13(a) is a graph of the complex viscosity of PLA0 and PLA2 as a function of angular frequency $(\omega)$. It could be seen from the figure that the angular frequency increased from 0 to $100 \mathrm{rad} \cdot \mathrm{s}^{-1}$, the complex viscosity of PLA2 decreased from $4259 \mathrm{~Pa} \cdot \mathrm{s}$ to $1413 \mathrm{~Pa} \cdot \mathrm{s}$; PLA0 decreased from $3352 \mathrm{~Pa} \cdot \mathrm{s}$ to $1025 \mathrm{~Pa} \cdot \mathrm{s}$. Both the complex viscosity of PLA0 and PLA2 showed a downward trend with increasing angular frequency, but at the same angular frequency value, the complex viscosity of PLA2 was greater than PLA0. Since the uniform dispersion of SGO-PS in the PLA matrix inhibited the movement of the PLA molecular chain and caused a higher flow resistance, the complex viscosity of PLA2 increased.

Figures 13(b) and 13(c) showed changes in storage modulus $\left(G^{\prime}\right)$ and loss modulus $\left(G^{\prime \prime}\right)$ with angular frequency. The loss modulus was the energy loss caused by the irreversible 
viscous deformation of the polymer material when it was deformed by external forces and reflected the viscous nature of the material [47]. It could be observed from Figure 13(b) that with increasing angular frequency from 0 to $100 \mathrm{rad} \cdot \mathrm{s}^{-1}$, the $\mathrm{G}^{\prime}$ and $\mathrm{G}^{\prime \prime}$ of PLA0 rose to $80859 \mathrm{~Pa}$ and $65644 \mathrm{~Pa}$, respectively; while the $G^{\prime}$ and $G^{\prime \prime}$ of PLA2, respectively, rose to $112644 \mathrm{~Pa}$ and $88568 \mathrm{~Pa}$. Both $\mathrm{G}^{\prime}$ and $\mathrm{G}^{\prime \prime}$ increased with increasing angular frequency, showing a linear rheological behavior, while PLA2's $G^{\prime}$ and $G^{\prime \prime}$ were higher than PLA0. The introduction of SGO-PS improved the elasticity and toughness of PLA. When the angular frequency was low, the PLA molecular chain and SGO-PS had enough time to unwrap, and the material had weak rebound ability after being stressed, resulting in a low storage modulus. When the angular frequency increased, the unwrapping time between the molecular chains was much greater than the deformation time of the material, so the unwrapping of the molecular chains could not keep up with the changes in external force deformation, which caused the system to exhibit elasticity, making the storage modulus and loss modulus greater than PLA0.

\section{Conclusion}

A modified graphite oxide (SGO) capable of initiating RAFT polymerization was prepared by the esterification reaction between the hydroxyl groups on the surface of GO and a chain transfer agent (trithiocarbonate). SGO as a macromolecular chain transfer agent, RAFT polymerization of styrene monomer was initiated with AIBN to obtain SGO-PS. FTIR and TGA tests showed the structure of the product, which confirmed that polystyrene was grafted to the surface of GO by RAFT polymerization, and the maximum grafting amount was $62.46 \%$ (wt). SGO-PS was introduced into the PLA matrix by melt intercalation, and the mechanical properties and thermal stability of PLA nanocomposites were significantly improved. The crystallinity was increased from $5.31 \%$ of PLA 0 to $32.51 \%$ of PLA2. Multiple melting behavior tests showed that the introduction of SGO-PS caused PLA molecular chains to be discharged into the unit cell in time, and the melting temperature shifted to a high temperature, which ultimately made PLA2's grain structure more complete and stable than PLA0. The rheological performance test proved that storage modulus, loss modulus, and complex viscosity were greatly improved. The above research results showed that the introduction of chemically modified GO in the PLA matrix could improve the comprehensive performance of PLA nanocomposites, which laid the foundation for the wider application and development of GO and PLA.

\section{Data Availability}

The raw/processed data required to reproduce these findings cannot be shared at this time as the data also forms part of an ongoing study.

\section{Conflicts of Interest}

The authors declare that they have no conflicts of interest.

\section{Acknowledgments}

Financial support from the University Research Program of Xinjiang Uygur Autonomous Region of China (XJEDU2018I003) is greatly acknowledged.

\section{References}

[1] V. Nagarajan, K. Zhang, M. Misra, and A. K. Mohanty, "Overcoming the fundamental challenges in improving the impact strength and crystallinity of PLA biocomposites: influence of nucleating agent and mold temperature," ACS Applied Materials \& Interfaces, vol. 7, no. 21, pp. 11203-11214, 2015.

[2] M. K. B. Bakri, E. Jayamani, S. Hamdan, M. R. Rahman, and A. Kakar, "Potential of Borneo Acacia wood in fully biodegradable bio-composites' commercial production and application," Polymer Bulletin, vol. 75, no. 11, pp. 5333-5354, 2018.

[3] Q. Jiang, X. Pei, L. Wu, T. T. Li, and J. H. Lin, "UV resistance and water barrier properties of $\mathrm{PP} / \mathrm{PLA} / \mathrm{MAH} / \mathrm{TiO}_{2}$ functional hybrid biocomposite films for packaging application," Advances in Polymer Technology, vol. 37, no. 8, pp. 29712980, 2018.

[4] L. Yang and W. Zhen, "Poly(lactic acid)/p-phenylenediamine functionalized graphene oxidized nanocomposites: preparation, rheological behavior and biodegradability," European Polymer Journal, vol. 121, article 109341, 2019.

[5] L. Yang and W. Zhen, "Preparation and characterization of phosphorylated graphene oxide grafted with poly(L-lactide) and its effect on the crystallization, rheological behavior, and performance of poly (lactic acid)," Polymers for Advanced Technologies, vol. 30, no. 11, pp. 2846-2859, 2019.

[6] H. Zhang and W. Zhen, "Performance, rheological behavior and enzymatic degradation of poly(lactic acid)/modified fulvic acid composites," International Journal of Biological Macromolecules, vol. 139, pp. 181-190, 2019.

[7] Z. Geng, W. Zhen, Z. Song, and X. Wang, "Synthesis, characterization of layered double hydroxide-poly(methylmethacrylate) graft copolymers via activators regenerated by electron transfer for atom transfer radical polymerization and its effect on the performance of poly(lactic acid)," Polymers for Advanced Technologies, vol. 29, no. 6, pp. 1765-1778, 2018.

[8] Z. Song and W. Zhen, "Performance and crystallization kinetics of poly (L-lactic acid) toughened by poly (D-lactic acid)," Advances in Polymer Technology, vol. 37, no. 6, pp. 15921607,2018

[9] P. Liu, W. Zhen, S. Bian, and X. Wang, "Preparation and performance of poly (lactic acid)/fulvic acid benzhydrazide composites," Advances in Polymer Technology, vol. 37, no. 8, pp. 2788-2798, 2018.

[10] X. Wang, J. Mi, J. Wang, H. Zhou, and X. Wang, "Multiple actions of poly(ethylene octene) grafted with glycidyl methacrylate on the performance of poly(lactic acid)," RSC Advances, vol. 8, no. 60, pp. 34418-34427, 2018.

[11] Y. Li, H. Zhou, B. Wen, Y. Chen, and X. Wang, "A facile and efficient method for preparing chain extended poly(lactic acid) foams with high volume expansion ratio," Journal of Polymers and the Environment, vol. 28, no. 1, pp. 17-31, 2020.

[12] L. Jia, B. Tong, D. Li, W. Zhang, and R. Yang, "Crystallization and flame-retardant properties of polylactic acid composites with polyhedral octaphenyl silsesquioxane," Polymers for Advanced Technologies, vol. 30, pp. 648-665, 2018. 
[13] C. P. Wu, C. C. Wang, and C. Y. Chen, "Enhancing the PLA Crystallization Rate and Mechanical Properties by Melt Blending with Poly(styrene-butadiene-styrene) Copolymer," Polymer-Plastics Technology and Engineering, vol. 54, no. 10, pp. 1043-1050, 2015.

[14] Y. Yang, L. Zhang, Z. Xiong, Z. Tang, R. Zhang, and J. Zhu, "Research progress in the heat resistance, toughening and filling modification of PLA," Science China Chemistry, vol. 59, no. 11, pp. 1355-1368, 2016.

[15] R. M. Rasal, A. V. Janorkar, and D. E. Hirt, "Poly(lactic acid) modifications," Progress in Polymer Science, vol. 35, no. 3, pp. 338-356, 2010.

[16] S. Castillejos, J. Cerna, F. Meléndez et al., "Bulk Modification of Poly(lactide) (PLA) via Copolymerization with Poly(propylene glycol) Diglycidylether (PPGDGE)," Polymers, vol. 10, no. 11, p. 1184, 2018.

[17] J. Liu, C. Peizhen, H. Jiang, and L. Chen, "Synthesis and chain extension of hydroxyl-terminated poly(lactic acid) oligomers and application in the blends," Polymer Composites, vol. 34, no. 2, pp. 305-312, 2013.

[18] F. Hassouna, J.-M. Raquez, F. Addiego, V. Toniazzo, P. Dubois, and D. Ruch, "New development on plasticized poly(lactide): chemical grafting of citrate on PLA by reactive extrusion," European Polymer Journal, vol. 48, no. 2, pp. 404-415, 2012.

[19] M. Hesami and A. Jalali-Arani, "Morphology development via static crosslinking of (polylactic acid/acrylic rubber) as an immiscible polymer blend," Macromolecular Materials and Engineering, vol. 303, no. 3, article 1700446, 2018.

[20] E. Fortunati, D. Puglia, A. Iannoni, A. Terenzi, J. M. Kenny, and L. Torre, "Processing Conditions, Thermal and Mechanical Responses of Stretchable Poly (Lactic Acid)/Poly (Butylene Succinate) Films," Materials, vol. 10, no. 7, p. 809, 2017.

[21] R. Das, S. L. Banerjee, and P. P. Kundu, "Fabrication and characterization of in situ graphene oxide reinforced highperformance shape memory polymeric nanocomposites from vegetable oil," RSC Advances, vol. 6, no. 33, pp. 2764827658, 2016.

[22] H. Mohamud, P. Ivanov, B. C. Russell, P. H. Regan, and N. I. Ward, "Selective sorption of uranium from aqueous solution by graphene oxide-modified materials," Journal of Radioanalytical and Nuclear Chemistry, vol. 316, no. 2, pp. 839-848, 2018.

[23] X. Wang, J. Mi, H. Zhou, and X. Wang, "Transition from microcellular to nanocellular chain extended poly(lactic acid)/hydroxyl-functionalized graphene foams by supercritical $\mathrm{CO}_{2}$," Journal of Materials Science, vol. 54, no. 5, pp. 38633877, 2019.

[24] H. Roghani-Mamaqani and V. Haddadi-Asl, "In-plane functionalizing graphene nanolayers with polystyrene by atom transfer radical polymerization: Grafting from hydroxyl groups," Polymer Composites, vol. 35, no. 2, pp. 386-395, 2014.

[25] L. Zheng and W. Zhen, "Surface Functionalization of Graphene Oxide via Activators Regenerated by Electron Transfer for Atom Transfer Radical Polymerization and Its Effect on the Performance of Poly(lactic acid)," Polymer Korea, vol. 42, no. 4, pp. 581-593, 2018.

[26] T. Guo, L. Zhang, H. Jiang et al., "Catalytic amounts of sodium hydroxide as additives for iron-mediated AGET ATRP of MMA," Polymer Chemistry, vol. 2, no. 10, p. 2385, 2011.

[27] A. Favier and M.-T. Charreyre, "Experimental Requirements for an Efficient Control of Free-Radical Polymerizations via the Reversible Addition-Fragmentation Chain Transfer (RAFT) Process," Macromolecular Rapid Communications, vol. 27, no. 9, pp. 653-692, 2006.

[28] M. Kannan and R. Dhamodharan, "Kinetic studies on star polymerization of styrene, MA and MMA using new three and four arm chain transfer agents (CTAs): the role of Rgroup structure present in the CTA on RAFT polymerization," Journal of Macromolecular Science, Part A, vol. 48, no. 9, pp. 722-736, 2011.

[29] Y. Yang, X. Song, L. Yuan et al., "Synthesis of PNIPAM polymer brushes on reduced graphene oxide based on click chemistry and RAFT polymerization," Journal of Polymer Science Part A: Polymer Chemistry, vol. 50, no. 2, pp. 329-337, 2012.

[30] M. Nikdel, M. Salami-Kalajahi, and M. Salami Hosseini, "Synthesis of poly(2-hydroxyethyl methacrylate-co-acrylic acid)grafted graphene oxide nanosheets via reversible addition-fragmentation chain transfer polymerization," RSC Advances, vol. 4 , no. 32, 2014.

[31] W. S. Hummers Jr. and R. E. Offeman, "Preparation of Graphitic Oxide," Journal of the American Chemical Society, vol. 80, no. 6, p. 1339, 1958.

[32] L. Zheng, Z. Geng, and W. Zhen, "Preparation, characterization, and reaction kinetics of poly (lactic acid)/amidated graphene oxide nanocomposites based on reactive extrusion process," Journal of Polymer Research, vol. 26, no. 3, 2019.

[33] V. G. Kumar, M. R. Rao, T. R. Guruprasad, and K. V. C. Rao, "Correlation of mechanical property, crosslink density and thermogravimetric behavior of castor oil polyurethane-polystyrene divinyl benzene simultaneous IPN networks," Journal of Applied Polymer Science, vol. 34, no. 5, pp. 1803-1815, 1987.

[34] K. Liu, L. Chen, Y. Chen et al., "Preparation of polyester/reduced graphene oxide composites via in situ melt polycondensation and simultaneous thermo-reduction of graphene oxide," Journal of Materials Chemistry A, vol. 21, no. 24, 2011.

[35] J. Liu, C. Y. Hong, and C. Y. Pan, "Dihydroxyl-terminated telechelic polymers prepared by RAFT polymerization using functional trithiocarbonate as chain transfer agent," Polymer, vol. 45, no. 13, pp. 4413-4421, 2004.

[36] Y. Guo, Z. Wang, H. Shao, and X. Jiang, "Hydrothermal synthesis of highly fluorescent carbon nanoparticles from sodium citrate and their use for the detection of mercury ions," Carbon, vol. 52, pp. 583-589, 2013.

[37] E. Casero, C. Alonso, L. Vázquez et al., "Comparative response of biosensing platforms based on synthesized graphene oxide and electrochemically reduced graphene," Electroanalysis, vol. 25, no. 1, pp. 154-165, 2013.

[38] W. Wang, D. He, X. Zhang et al., "Synthesis of Gold Nanoparticles with Graphene Oxide," Journal of Nanoscience and Nanotechnology, vol. 14, no. 5, pp. 3412-3416, 2014.

[39] B. Yang, D. Wang, F. Chen et al., "Melting and Crystallization Behaviors of Poly(Lactic Acid) Modified with Graphene Acting as a Nucleating Agent," Science, Part B. Physics, vol. 58, no. 2 , pp. 290-304, 2019.

[40] H. Ismail, S. Shuhelmy, and M. R. Edyham, "The effects of a silane coupling agent on curing characteristics and mechanical properties of bamboo fibre filled natural rubber composites," European Polymer Journal, vol. 38, no. 1, pp. 39-47, 2002.

[41] Y. Kong and J. N. Hay, "The enthalpy of fusion and degree of crystallinity of polymers as measured by DSC," European Polymer Journal, vol. 39, no. 8, pp. 1721-1727, 2003. 
[42] D. Garlotta, "A Literature Review of Poly(Lactic Acid)," Journal of Polymers and the Environment, vol. 9, no. 2, pp. 63-84, 2001.

[43] O. C. Wokadala, S. S. Ray, J. Bandyopadhyay, J. Wesley-Smith, and N. M. Emmambux, "Morphology, thermal properties and crystallization kinetics of ternary blends of the polylactide and starch biopolymers and nanoclay: the role of nanoclay hydrophobicity," Polymer, vol. 71, pp. 82-92, 2015.

[44] L. Zhao, X. Liu, R. Zhang, H. He, T. Jin, and J. Zhang, "Unique Morphology in Polylactide/Graphene Oxide Nanocomposites," Journal of Macromolecular Science Part B-Physics, vol. 54, no. 1, pp. 45-57, 2014.

[45] M. Yasuniwa, K. Sakamo, Y. Ono, and W. Kawahara, "Melting behavior of poly(L-lactic acid): X-ray and DSC analyses of the melting process," Polymer, vol. 49, no. 7, pp. 1943-1951, 2008.

[46] V. Asadi, S. H. Jafari, H. A. Khonakdar, L. Häubler, and U. Wagenknecht, "Incorporation of inorganic fullerene-like $\mathrm{WS}_{2}$ into poly(ethylene succinate) to prepare novel biodegradable nanocomposites: a study on isothermal and dynamic crystallization," RSC Advances, vol. 6, no. 6, pp. 4925-4935, 2016.

[47] W. Zhen and W. Wang, "Structure, properties and rheological behavior of thermoplastic poly(lactic acid)/quaternary fulvic acid-intercalated saponite nanocomposites," Polymer Bulletin, vol. 73, no. 4, pp. 1015-1035, 2016. 